Board of Governors of the Federal Reserve System

International Finance Discussion Papers

Number 601

January 1998

\title{
THE CHOICE OF A MONETARY POLICY REACTION FUNCTION IN A SIMPLE OPTIMIZING MODEL
}

\author{
Dale W. Henderson and Jinill Kim
}

NOTE: International Finance Discussion Papers are preliminary materials circulated to stimulate discussion and critical comment. References in publications to International Finance Discussion Papers (other than an acknowledgment that the writer has had access to unpublished material) should be cleared with the author or authors. Recent IFDPs are available on the Web at www.bog.frb.fed.us. 


\title{
THE CHOICE OF A MONETARY POLICY REACTION FUNCTION IN A SIMPLE OPTIMIZING MODEL
}

\author{
Dale W. Henderson and Jinill Kim*
}

\begin{abstract}
Monetary policy reaction functions are compared in a simple optimizing model with one-period nominal stickiness, i.i.d. shocks, and no capital accumulation. The interest rate is the instrument and is either kept constant, "interest rate targeting" for short, or used in targeting one of the following: money, the price level, output, nominal income (output), money growth, inflation, and the sum of inflation and output. There are three varieties of one-period nominal stickiness---wage stickiness, wage and price stickiness, and price stickiness---and three kinds of shocks---money demand shocks, goods demand shocks, and productivity shocks. A given type of targeting is "better" than some other type for a given variable and kind of shock if it results in smaller deviations of the variable from its target value. Some familiar results regarding the ranking of types of targeting are confirmed in the optimizing model, and some new results are obtained. It is not surprising that rankings may depend both on the type of shock and on which variable is the target variable. However, it may be somewhat surprising that, given that wages are sticky, rankings depend on whether prices are sticky, but that given that prices are sticky rankings do not depend on whether wages are sticky.
\end{abstract}

Keywords: monetary policy, reaction function, inflation targeting, price level targeting, interest rate targeting, nominal stickiness

\footnotetext{
* Henderson and Kim are, respectively, economists in the International Finance Division and the Division of Research and Statistics of the Federal Reserve Board. Earlier versions were presented at the Federal Reserve Board, the International Economic Association (IEA) Conference on "Monetary Theory as a Basis for Monetary Policy," the fall 1997 Federal Reserve System (FRS) Conference on Macroeconomics, the Federal Reserve Bank of Chicago, and the Money and Banking Workshop at the University of Chicago. The authors would like to thank Luigi Bonatti and Francesco Farina, their discussants at the IEA Conference, Alexander Wolman, their discussant at the FRS Conference, Flint Brayton, and James Dow for helpful comments; Neva Kerbeshian for valuable research assistance; Evelyn Reynolds for effective graphic design; and Steven Sumner for thoughtful editorial suggestions. This paper represents the views of the authors and should not be interpreted as reflecting those of the Board of Governors of the Federal Reserve System or of any other person associated with the Federal Reserve System.
} 


\section{Introduction}

This paper is an exercise in stabilization economics. We analyze the choice of a monetary policy reaction function using the standard approach originated by Bailey (1962) and extended by Poole (1970), and our title is patterned after Poole's.

We consider two "general" specifications for a monetary policy reaction function: a "levels" reaction function and a "combination" reaction function. In both specifications, the interest rate is the instrument of monetary policy. In the levels specification, the interest rate responds to deviations of the money supply, the price level, and the level of output from chosen values. In the combination specification, the interest rate responds to deviations of the growth in the money supply, the rate of inflation, and the level of output from chosen values. These two specifications have almost all popular monetary policy reaction functions as special cases. The special cases that we consider here are keeping the interest rate instrument constant, referred to for brevity as "interest rate targeting," and using the interest rate instrument in targeting exactly one of the following: money, the price level, output, nominal income (output), money growth, inflation, and the sum of inflation and output. ${ }^{1}$

Our analytical framework is an optimizing model with nominal stickiness that is "up to date" in the sense that it is similar to those analyzed by others recently. ${ }^{2}$ We call our model "simple" because it has one-period nominal stickiness, i.i.d. shocks, and no capital accumulation. ${ }^{3}$

Our model incorporates the increasingly popular paradigm with monopolistic competition among firms and monopsonistic competition among workers crafted by Blanchard and Kiyotaki (1987) using insights from Dixit and Stiglitz (1977). As is no doubt widely recognized, this paradigm does not account for the presence of nominal stickiness, one of the two major explanations for the existence of a "stabilization problem." 4 That is, the nominal stickiness in models embodying this paradigm, as

1 "Interest rate targeting" and money supply targeting are considered by Bailey (1962) and Poole (1970) and also by Bryant, Henderson, and Parkin. Nominal income targeting is suggested by Corden, Meade, and Tobin: analyzed extensively by Bean (1983): and further analyzed by Aizenman and Frenkel; Argy; Asako and Wagner; Frankel; Frankel and Chinn; Frenkel, Goldstein, and Masson; Fukuda and Hamada; Marston; Meltzer; Reinhart; Taylor; and West. Targeting a combination of inflation and output is investigated in several of the chapters in Bryant, Hooper, and Mann (1993), including Henderson and McKibbin (1993a), and in Henderson and McKibbin (1993b) and is found to be consistent with U.S. data for the period after 1982 by Taylor (1993). A rule involving targeting a combination of inflation and output is often referred to as a Taylor rule. Citations for the contributions of the authors mentioned but not cited in this footnote are contained in the two Henderson and McKibbin pieces.

${ }^{2}$ Most of the recent papers that make use of optimizing models with nominal stickiness are cited in Cooley and Hansen (1995) or Goodfriend and King (1997).

${ }^{3}$ The analysis of non-overlapping contracts of the type used in this paper was pioneered by Gray (1976) (one-period contracts) and Fischer (1977) (two-period contracts). One-period contracts in optimizing models are considered by Cho (1993) and Dow (1995) (wage and price separately), Benassy (1995) (wage) and Beaudry and Devereux (1995) (price). All of these authors assume serially correlated productivity and money growth shocks. Multiperiod overlapping contracts are considered by King (1991) (price and wage) and Cho and Cooley (1995) (wage).

${ }^{4}$ The other major explanation is that even without nominal stickiness there may be multiple (Pareto rankable) equilibria, so there may be a "coordination problem." 
in most if not all other models, is ad hoc. Nonetheless, this paradigm represents a step forward because it provides a plausible description of how agents might behave if nominal stickiness is assumed. In particular, under this paradigm within a range it is profitable for firms to produce more output and for workers to supply more labor if the demand for output turns out to be higher than expected.

Models like ours that incorporate nominal stickiness and the new paradigm are properly viewed as extensions of earlier "disequilibrium models," because both classes of models require specifications of how agents behave in the presence of ad hoc nominal rigidities. $^{5}$ The close connection between today's and earlier disequilibrium models is particularly obvious in the simple model of this paper. In order to emphasize this connection, we choose the modifier "notional" for the version of our model with flexible wages and prices.

The relative attractiveness of alternative monetary policy reaction functions depends both on the type of shock that hits the economy and on the type of nominal stickiness that exists in the economy. We consider three kinds of shocks: money demand shocks, goods demand shocks, and productivity shocks. All of them are included in the specification of the model from the outset rather than being "tacked on" at some later stage of the analysis. Furthermore, all of them are shocks to the "technology" that constrains the optimization of agents not to the "tastes" of the agents, so, in principle, the effects of these shocks under alternative types of targeting can be compared using the utility function of the representative agent.

We consider three types of one-period nominal stickiness: wage stickiness, wage and price stickiness, and price stickiness. In addition, in solving for the rational expectations equilibrium of the model we consider what happens when wages and prices are perfectly flexible.

In this paper we rank different types of targeting for a given variable and a given type of shock. We say that a given type of targeting is "better" than some other type for a given variable and a given type of shock if the deviation of the given variable from its target value for the given type of shock is less with the given type of targeting, and we use the symbol " $\succ$ " to represent the words "is better than." This way of ranking regimes facilitates comparison of our results with those from most of the existing stabilization literature. An attractive alternative way of ranking regimes for different shocks is to use the utility function of the representative agent. ${ }^{6}$

\section{The Notional Model}

In this section we consider the notional model that is used as the point of departure for our analysis of monetary policymaking with nominal stickiness. This model deter-

\footnotetext{
${ }^{5}$ Patinkin is among the first to use a disequilbrium model, and Clower is both an important developer of such models and a persuasive advocate of their use. Barro and Grossman provide an early systematic analysis of these models. Other important contributors to the analysis of disequilibrium models are Benassy, Grandmont, Henin, Malinvaud, Negishi, and Portes. Citations for the contributions mentioned but not cited in this note can be found in Quandt (1987)

${ }^{6}$ Clarida, Gali, and Gertler (1997) cite several studies that use this approach.
} 
mines the actions that agents would take if wages and prices were perfectly flexible. Variables are defined in Table 1. Except for the interest rate, the inflation rate, and the money growth rate, large letters stand for the levels of variables and small letters for the deviations of logarithms of variables from their unconditional expected values. Time subscripts are suppressed except when they are needed for clarity.

Table 1: Definitions of Variables

$\begin{array}{llll}Y_{f}, Y & \text { outputs } & T_{h}, T & \text { taxes } \\ L_{f}, L_{h}, L & \text { labor amounts } & G & \text { government spending } \\ P_{f}, P & \text { prices } & I=1+i & \text { gross nominal interest rate } \\ W_{h}, W & \text { nominal wages } & \Pi=1+\pi & \text { gross inflation rate } \\ D_{h}, D & \text { consumption realizations } & \mathcal{M}=1+\mu & \text { gross money growth rate } \\ C_{h}, C & \text { consumption purchases } & X_{f}, X & \text { productivity shocks } \\ M_{h}, M & \text { nominal money holdings } & \mathbf{V}_{\mathbf{h}}, \mathbf{V} & \text { money demand shocks } \\ B_{h}, B & \text { nominal bond holdings } & \mathbf{U}_{\mathbf{h}}, \mathbf{U} & \text { goods demand shocks }\end{array}$

\subsection{Firms}

There are $n_{f}$ "identical" monopolistically competitive firms, where $n_{f}$ is normalized to 1 . The problem of the $f$ th firm is to find the ${ }^{7}$

$$
\max _{\left\{L_{f}\right\}}\left(\frac{P_{f}}{P} Y_{f}-\frac{W}{P} L_{f}\right)
$$

Its output is given by its production function, ${ }^{8}$

$$
Y_{f}=L_{f}^{1-\alpha} X_{f}
$$

where $L_{f}$ is the amount of a bundle of labor composed of equal amounts of the labor of all households that it employs, $X_{f}$ is its productivity shock, and $\bar{X}_{f}=1$. The inverse demand function for its product, ${ }^{9}$

$$
\frac{P_{f}}{P}=\left(\frac{Y_{f}}{Y}\right)^{-\frac{\tau_{Y}-1}{\tau_{Y}}},
$$

gives its relative price as a decreasing function of its relative output. To maximize profits a firm must hire labor up to the point at which the marginal value product of

\footnotetext{
${ }^{7} L_{f}$ and $W$ are defined as $L_{f}=\left(\sum_{h=1}^{n_{h}}\left(L_{f h}\right)^{\frac{1}{\tau_{L}}}\right)^{\tau_{L}}$ and $W=\left(\sum_{h=1}^{n_{h}}\left(W_{h}\right)^{\frac{-1}{\tau_{L}-1}}\right)^{-\left(\tau_{L}-1\right)}$, respectively.

${ }^{8}$ That is, we assume for simplicity that there are no factors of production other than labor and no fixed costs. Kim (1997a) shows that our formulation can be viewed as a model with capital in which the marginal adjustment cost for the first unit of net investment approaches infinity. Kim (1997c) explores the implications of allowing for fixed costs.

${ }^{9}$ This inverse demand function reflects the behavior of households which maximize utility given relative prices.
} 
labor equals the real wage:

$$
\frac{W}{P}=\left(\frac{1-\alpha}{\tau_{Y}}\right)\left(\frac{Y_{f}}{Y}\right)^{-\frac{\tau_{Y}-1}{\tau_{Y}}} L_{f}^{-\alpha} X_{f}
$$

Since $n_{f}=1$,

$$
L_{f}=L, \quad Y_{f}=Y, \quad \text { and } X_{f}=X .
$$

The equalities in (5) imply that the "aggregate production function" and "aggregate labor demand" are, respectively,

$$
\begin{gathered}
Y=L^{1-\alpha} X, \\
\frac{W}{P}=\left(\frac{1-\alpha}{\tau_{Y}}\right) L^{-\alpha} X .
\end{gathered}
$$

Loglinearizing, we obtain the first two equations in Table 2 below.

\subsection{Households}

There are $n_{h}$ identical households, where $n_{h}$ is normalized to 1 . The problem of the $h$ th household is to find the

$$
\max _{\left\{C_{h, s}, M_{h, s}, B_{h, s}, L_{h, s}\right\}} \mathcal{E}_{t}\left[\sum_{s=t}^{\infty} \beta^{s-t}\left(\frac{D_{h, s}^{1-\sigma}-1}{1-\sigma}-\left(\frac{1}{\breve{L}_{h}^{\chi}}\right) \frac{L_{h, s}^{1+\chi}}{1+\chi}\right)\right],
$$

subject to

$$
\begin{gathered}
C_{h, s}=\frac{W_{h, s}}{P_{s}} L_{h, s}+\frac{1}{n_{h}} \sum_{f=1}^{n_{f}}\left(\frac{P_{f, s}}{P_{s}} Y_{f, s}-\frac{W_{s}}{P_{s}} L_{f, s}\right) \\
-T_{h, s}-\frac{M_{h, s}-M_{h, s-1}+B_{h, s}-I_{h, s-1} B_{h, s-1}}{P_{s}} \\
D_{h, s}=C_{h, s}\left[1-\theta \exp \left(-\frac{M_{h, s}}{P_{s} C_{h, s}^{\kappa}} \frac{1}{\mathbf{V}_{\mathbf{h}, \mathbf{s}}}\right)\right]-\bar{D}_{h} \mathbf{U}_{\mathbf{h}, \mathbf{s}}, \\
\frac{W_{h, s}}{W_{s}}=\left(\frac{L_{h, s}}{L_{s}}\right)^{-\frac{\tau_{L}-1}{\tau_{L}}},
\end{gathered}
$$

where $\mathcal{E}_{t}$ indicates an expectation based on period $t$ information. According to equation (8), period utility depends positively on the consumption realization and negatively on labor supply, and the disutility of deviations of the ratio $\frac{L_{h, s}}{L_{s}}$ from one increases without limit as $\chi \rightarrow \infty$. The period budget constraint, equation (9), states that consumption expenditure must equal disposable income minus asset accumulation. The household receives one $n_{h}$ th of aggregate profits. According to equation (10), the consumption realization depends positively on consumption expenditure and real balances and negatively on the money demand shock and the goods demand shock. Each household is a monopsonistically competitive supplier of its unique labor input. The inverse demand function for its labor, equation (11), gives its relative 
wage as a decreasing function of its relative labor input. ${ }^{10}$ We impose the following parameter restrictions: $0<\beta<1, \kappa>0,0<\theta<1$, and $\chi \geq 0$ and assume that $\overline{\mathbf{V}}_{\mathrm{h}, \mathrm{t}}$ $=\mathcal{E}\left(\frac{M_{h, t}}{P_{h, t} C_{h, t}^{\kappa}}\right)$, where $\mathcal{E}$ indicates an unconditional expectation, and $\overline{\mathbf{U}}_{\mathbf{h}}=0 .{ }^{11}$

Substituting (10) into (8), substituting (11) into (9), constructing a Lagrangian expression with the multiplier $\eta_{h, t}$ associated with the period budget constraint for period $t$, and differentiating yields the first order conditions for period $t$ variables:

$$
\begin{gathered}
0=\frac{D_{h, t ; C_{h, t}}}{D_{h, t}^{\sigma}}-\eta_{h, t} \\
0=\frac{D_{h, t ; M_{h, t}}}{D_{h, t}^{\sigma}}+\beta \mathcal{E}_{t}\left(\frac{\eta_{h, t+1}}{P_{t+1}}\right)-\frac{\eta_{h, t}}{P_{t}} \\
0=\beta I_{t} \mathcal{E}_{t}\left(\frac{\eta_{h, t+1}}{P_{t+1}}\right)-\frac{\eta_{h, t}}{P_{t}} \\
0=-\left(\frac{L_{h, t}}{\breve{L}_{h}}\right)^{\chi}+\frac{\eta_{h, t}}{\tau_{L}} \frac{W_{h, t}}{P_{t}}
\end{gathered}
$$

where

$$
\begin{gathered}
D_{h, t ; C_{h, t}}=1-\theta \exp \left(-\frac{M_{h, t}}{P_{t} C_{h, t}^{\kappa}} \frac{1}{\mathbf{V}_{\mathbf{h}, \mathbf{t}}}\right)-\kappa \theta \frac{M_{h, t}}{P_{t} C_{h, t}^{\kappa}} \frac{1}{\mathbf{V}_{\mathbf{h}, \mathbf{t}}} \exp \left(-\frac{M_{h, t}}{P_{t} C_{h, t}^{\kappa}} \frac{1}{\mathbf{V}_{\mathbf{h}, \mathbf{t}}}\right), \\
P_{t} D_{h, t ; M_{h, t}}=\frac{\theta}{C_{h, t}^{\kappa-1} \mathbf{V}_{\mathbf{h}, \mathbf{t}}} \exp \left(-\frac{M_{h, t}}{P_{t} C_{h, t}^{\kappa}} \frac{1}{\mathbf{V}_{\mathbf{h}, \mathbf{t}}}\right) .
\end{gathered}
$$

Hereafter, we omit $t$ subscripts except when they are needed for clarity. Since $n_{h}=1$,

$$
\begin{gathered}
D_{h}=D, L_{h}=L, \breve{L}_{h}=\breve{L}, C_{h}=C, W_{h}=W, T_{h}=T, \\
M_{h}=M, B_{h}=B, \mathbf{U}_{\mathbf{h}}=\mathbf{U}, \mathbf{V}_{\mathbf{h}}=\mathbf{V}, \eta_{h}=\eta .
\end{gathered}
$$

\footnotetext{
${ }^{10}$ This inverse demand function reflects the behavior of firms which maximize profits given relative wages.

${ }^{11} C_{h}$ and $P$ are defined as $C_{h}=\left(\sum_{f=1}^{n_{f}}\left(C_{f h}\right)^{\frac{1}{\tau_{Y}}}\right)^{\tau_{Y}}$ and $P=\left(\sum_{f=1}^{n_{f}}\left(P_{f}\right)^{\frac{-1}{\tau_{Y}-1}}\right)^{-\left(\tau_{Y}-1\right)}$, respectively. The expression for $D_{t}$ in equation (10) has the properties that

$$
\lim _{\frac{M_{t}}{P_{t}} \rightarrow 0} D_{t}>0, \quad \lim _{\frac{M_{t}}{P_{t}} \rightarrow \infty} D_{t}>C_{t}, \quad \text { and } \quad \lim _{\frac{M_{t}}{P_{t} C_{t}^{k}} \rightarrow \bar{V}} D_{t}>(1-\theta) C_{t},
$$

Another plausible specification of the relationship between $C_{t}$ and $D_{t}$ that has the same properties if $\theta=a /(1+b)$ is$$
D_{t}=C_{t}\left[1-a\left(1+b \frac{M_{t}}{P_{t} C_{t}^{\kappa}} \frac{1}{V_{t}}\right)^{-1}\right]-\bar{D} U_{t} .
$$

We chose the specification in the text for simplicity. Another way of taking account of transactions costs would be to subtract them from output produced in order to obtain the output available for use by agents.
} 
Therefore, the "aggregate first-order conditions" are

$$
\begin{gathered}
0=\frac{D_{C}}{D^{\sigma}}-\eta \\
0=\frac{D_{M}}{D^{\sigma}}+\beta \mathcal{E}\left(\frac{\eta_{+1}}{P_{+1}}\right)-\frac{\eta}{P} \\
0=\beta I \mathcal{E}\left(\frac{\eta_{+1}}{P_{+1}}\right)-\frac{\eta}{P} \\
0=-\left(\frac{L}{\breve{L}}\right)^{\chi}+\frac{\eta}{\tau_{L}} \frac{W}{P}
\end{gathered}
$$

where

$$
\begin{gathered}
D_{C}=1-\theta \exp \left(-\frac{M}{P C^{\kappa}} \frac{1}{\mathbf{V}}\right)-\kappa \theta \frac{M}{P C^{\kappa}} \frac{1}{\mathbf{V}} \exp \left(-\frac{M}{P C^{\kappa}} \frac{1}{\mathbf{V}}\right), \\
P D_{M}=\frac{\theta}{C^{\kappa-1} \mathbf{V}} \exp \left(-\frac{M}{P C^{\kappa}} \frac{1}{\mathbf{V}}\right) .
\end{gathered}
$$

The equalities in (18) imply that $\overline{\mathbf{V}}=\mathcal{E}\left(\frac{M}{P C^{\kappa}}\right)$, so the logarithmic differentials of $D_{C}, D_{M}$, and $D^{\sigma}$ are

$$
\begin{gathered}
\widehat{D_{C}}=\frac{\theta}{e-\theta-\kappa \theta}(m-p-\kappa c-\mathbf{v}), \\
\widehat{P D_{M}}=c-m+p, \\
\widehat{D^{\sigma}}=\frac{e-\theta-\kappa \theta}{e-\theta} \sigma c+\frac{\theta}{e-\theta} \sigma(m-p-\mathbf{v})-\sigma \mathbf{U},
\end{gathered}
$$

Using (19) to eliminate $\eta$ in (22) yields a "labor supply" equation with the logarithmic approximation

$$
\chi l=-\delta c-\zeta(m-p-\mathbf{v})+\sigma \mathbf{U}+(w-p),
$$

and using (19) for today and the expectation of (19) for tomorrow based on today's information to eliminate $\frac{\eta}{P}$ and $\mathcal{E}\left(\frac{\eta_{+1}}{P_{+1}}\right)$ in $(21)$ yields a consumption Euler equation with the logarithmic approximation

$$
\delta c+\zeta(m-p-\mathbf{v})-\sigma \mathbf{U}=\delta c_{+1 \mid}+\zeta\left(m_{+1}-p_{+1 \mid}-\mathbf{v}_{+\mathbf{1} \mid}\right)-\left(i_{t}-\pi_{+1 \mid}\right)-\sigma \mathbf{U}_{+\mathbf{1} \mid}
$$

where the subscript $+1 \mid$ attached to a variable indicates the expectation of tomorrow's value of that variable based on today's information. In equations (28) and (29)

$$
\begin{aligned}
\delta & =\left(\frac{e-\theta-\kappa \theta}{e-\theta}\right) \sigma+\frac{\kappa \theta}{e-\theta-\kappa \theta}=\sigma+\frac{\kappa \theta}{e-\theta}\left(\frac{e-\theta}{e-\theta-\kappa \theta}-\sigma\right), \\
\zeta & =\left(\frac{\theta}{e-\theta}\right) \sigma-\frac{\theta}{e-\theta-\kappa \theta}=\left(\frac{\theta}{e-\theta}\right)\left(\sigma-\frac{e-\theta}{e-\theta-\kappa \theta}\right) .
\end{aligned}
$$

To simplify the analysis and to facilitate comparison of our results with those from the many models in which the utility function is additively separable in consumption 
and real balances, we focus on the special case of our model in which $\frac{e-\theta}{e-\theta-\kappa \theta}-\sigma=0$ so that $\delta=\sigma$ and $\zeta=0 .{ }^{12}$ In this special case, the logarithmic approximations of the labor supply and consumption Euler equations become, respectively,

$$
\begin{aligned}
\chi l & =-\sigma c+U+(w-p) \\
\sigma c-U & =\sigma c_{+1 \mid}-\left(i-\pi_{+1 \mid}\right)-U_{+1 \mid},
\end{aligned}
$$

where $\sigma \mathbf{U}=U$. Interpreting $M$ as the money supply and using (21) to eliminate $\mathcal{E}\left(\frac{\eta_{+1}}{P_{+1}}\right)$ in $(20)$ and (19) to eliminate $\frac{\eta}{P}$ in the resulting equation yield an equation for money market equilibrium with the logarithmic approximation ${ }^{13}$

$$
m-p=\phi c-\varepsilon i+v,
$$

where

$$
\begin{aligned}
\phi & =\frac{e-\theta}{e-\kappa \theta} \\
\varepsilon & =\frac{\beta}{(1-\beta)} \frac{e-\theta-\kappa \theta}{e-\kappa \theta} \\
v & =\left(\frac{\theta}{e-\kappa \theta}\right) \mathbf{v} .
\end{aligned}
$$

\section{3 "Fiscal" Policy}

In recent years it has been recognized that "fiscal" policy and "monetary" policy are interrelated in the sense that assumptions about the paths of government spending and taxes have implications for which "monetary" policies are feasible and for the effects of different feasible monetary policies. ${ }^{14}$ The interaction between "fiscal" policy and "monetary" policy is an interesting and important topic. However, it is not the topic of this paper. Therefore, we impose some simple assumptions about the paths of government spending and taxes under which we can study alternative monetary policy reaction functions. In particular, we assume that the government budget is balanced period by period and that real government spending is always zero: ${ }^{15}$

$$
\begin{gathered}
G+\frac{i_{-1} B_{-1}}{P}-T=0 \\
G=0
\end{gathered}
$$

\footnotetext{
${ }^{12}$ This condition can be met only if $\sigma$ is greater than 1 , but not "too large."

${ }^{13}$ In our model the "activity variable" in the money demand function is consumption. It is possible to construct models in which the activity variable is output. It does not matter which specification is chosen in our model with no investment or government spending, but as shown by Erceg (1997) it can matter in a model with capital accumulation.

${ }^{14}$ Bryant (1980) and Sargent and Wallace (1981) call attention to the importance of the interrelationship between "fiscal" policy and "monetary" policy. Leeper (1991), Sims (1994), Woodford (1996), and Canzoneri and Diba (1997) make significant advances in the analysis of this relationship.

${ }^{15}$ We assume that the expected rate of inflation, the solution for inflation in the notional model when all shocks take on their mean values, is equal to zero. The analysis could be modified to allow for a nonzero expected rate of inflation. If the expected rate of rate of inflation were positive, the expected government deficit would have to be positive.
} 


\section{4 "Monetary" Policy}

As stated in the introduction, "monetary" policy is characterized by one or another monetary policy reaction function. We assume throughout that the interest rate is the instrument of monetary policy. We consider two "general" specifications for a monetary policy reaction function: a "levels" reaction function and a "combination" reaction function. Our reasons for naming the two reaction functions as we do should be clear after we describe them. Almost all commonly considered specifications of monetary policy are special cases of these reaction functions. We refer to the model with the levels reaction function as the "levels model" and the model with the combination reaction function as the "combination model."

The levels reaction function is

$$
\frac{I}{\bar{I}}=\Lambda\left(\frac{P}{\bar{P}}, \frac{Y}{\bar{Y}}, \frac{M}{\bar{M}}\right)
$$

where $\bar{P}$ is the target price level; $\bar{Y}$ is expected output, the solution for output in the notional model when all shocks take on their mean values; $\bar{I}$ is the gross nominal interest rate consistent with the price level and output being constant at their target and expected values, respectively; and $\bar{M}$ is the target level of the money supply, the level of the money supply that is consistent with $P, Y$, and $I$ being equal to $\bar{P}, \bar{Y}$, and $\bar{I}$, respectively. ${ }^{16} 17$

The loglinearized version of the levels reaction function is ${ }^{18}$

$$
i=\lambda_{m} m+\lambda_{y} y+\lambda_{p} p .
$$

The "nominal anchors" in the levels model are money supply and the price level. As is shown in Appendix A, the levels model has a unique solution only if the sum of the responses of the interest rate to deviations of these nominal anchors from their target values exceeds zero, that is, only if $\lambda_{m}+\lambda_{p}>0$. We focus on several types of targeting that are special cases of the levels reaction function. Price level targeting, output targeting in the levels case, nominal income (output) targeting,

${ }^{16}$ We assume that the target value of the price level is constant and equal to one for simplicity. It is straightforward to generalize the analysis to the case in which the target value increases at a constant rate over time, and $\bar{I}$ reflects that rate of increase. The essential feature of price level targeting is that the monetary policy maker tries to move today's price level toward a prespecified target value no matter what the value of yesterday's price level.

${ }^{17} \bar{L}$, the solution for labor in the notional model when all disturbances take on their mean values, is given by

$$
\bar{L}=\left[(1-\alpha) \bar{X}^{1-\sigma}\right]^{\frac{1}{\chi+\alpha+(1-\alpha) \sigma}} \breve{L} \frac{\chi}{\chi+\alpha+(1-\alpha) \sigma} .
$$

It follows that $\bar{L} \rightarrow \breve{L}$ as $\chi \rightarrow \infty$.

${ }^{18}$ We do not allow for purely exogenous changes in the interest rate. If we did the reaction function would be

$$
i=\lambda_{m} m+\lambda_{y} y+\lambda_{p} p+f .
$$

where, for example, $f$ is an i.i.d. shock. 
and money stock targeting are limiting cases in which the response of the interest rate to deviations from target in $p, y, p+y$, and $m$, respectively, approach infinity. "Interest rate targeting" is a shorthand way of referring to the limiting case in which the responses of the interest rate instrument to changes in $m, p$, and $y$ approach zero.

The combination reaction function is

$$
\frac{I}{\bar{I}}=\Gamma\left(\frac{\Pi}{\bar{\Pi}}, \frac{Y}{\bar{Y}}, \frac{\mathcal{M}}{\overline{\mathcal{M}}}\right)
$$

where $\bar{\Pi}$ is the target gross rate of inflation; $\bar{Y}$ is expected output, the solution for output in the notional model when all shocks take on their mean values; $\bar{I}$ is the gross nominal interest rate consistent with the gross inflation rate and output being constant at their target and expected values, respectively; and $\overline{\mathcal{M}}$ is the target gross rate of growth of money, the rate of growth of money that is consistent with $\Pi, Y$, and $I$ being equal to $\bar{\Pi}, \bar{Y}$, and $\bar{I}$, respectively. ${ }^{19}$

The loglinearized version of the combination reaction function is

$$
i=\gamma_{\mu} \mu+\gamma_{y} y+\gamma_{\pi} \pi
$$

The nominal anchors in the combination model are the money growth rate and the inflation rate. As is shown in Appendix A, the combination model has a unique solution only if the sum of the responses of the interest rate to deviations of these nominal anchors from their target values exceeds unity, that is, only if $\gamma_{\mu}+\gamma_{\pi}>1$. We focus on several types of targeting that are special cases of the combination reaction function. Inflation targeting, output targeting in the combination case, inflation plus output targeting, and money growth targeting are limiting cases in which the response of the interest rate to deviations from target in $\pi, y, \pi+y$, and $\mu$, respectively, approach infinity. With the combination reaction function there is no sensible limiting case that can be thought of as "interest rate targeting."

Allowing $\gamma_{\mu}$ to be positive instead of zero complicates the analysis substantially. However, it is important to consider this case because many analysts have suggested that $\mu$ should be included in the monetary policy reaction function and because the case of $\gamma_{\mu} \rightarrow \infty$ is a standard case in the theoretical literature on monetary policy in optimizing models. ${ }^{20}$

\subsection{Equilibrium}

In this subsection we discuss equilibrium in the levels model and in the combination model. We assume that the shocks are i.i.d.

\footnotetext{
${ }^{19}$ We assume that the target gross inflation rate is one or, equivalently, that the target inflation rate is zero for simplicity. It is straightforward to generalize the analysis to the case in which the target inflation rate is positive, and $\bar{I}$ reflects that positive target rate. The essential feature of inflation targeting is that the monetary policy maker tries to move today's price level toward a level that depends on yesterday's price level.

${ }^{20}$ Cho (1993), Cho and Cooley (1995), and Benassy (1995) assume that the money growth rate is exogenous. However, Leeper (1991), Sims (1994), Woodford (1996), and Kim (1997b) assume that monetary policy is governed by reaction functions similar to some of those considered in this paper.
} 
Table 2: The Notional Models

$$
\begin{array}{lll}
y=(1-\alpha) l+x & \text { production function } & \mathrm{T} 2-1 \\
p-w=\alpha l-x & \text { labor demand } & \mathrm{T} 2-2 \\
w-p=\chi l+\sigma y-U & \mathrm{~T} 2-3 \\
\begin{array}{l}
\sigma y=-\left[i-\left(p_{+1 \mid}-p\right)\right]+U+\sigma y_{+1 \mid}-U_{+1 \mid} \\
m=p+\phi y-\varepsilon i+v
\end{array} & \begin{array}{l}
\text { labor supply } \\
\text { money mate demand }
\end{array} & \mathrm{T} 2-4 \\
i=\lambda_{m} m+\lambda_{y} y+\lambda_{p} p & \text { levels reaction function } & \mathrm{T} 2-6 \\
i=\gamma_{\mu} \mu+\gamma_{y} y+\gamma_{\pi} \pi & & \\
\pi=p-p_{-1} & \text { combination reaction function } & \mathrm{T} 2-7 \\
\mu=m-m_{-1} & \text { inflation definition } & \mathrm{T} 2-8 \\
& \text { money growth definition } & \mathrm{T} 2-9
\end{array}
$$

Table 2 contains the equations that form the basis of our analysis. The notional levels model comprises equations (T2-1) - (T2-6), and the notional combination model comprises equations (T2-1) - (T2-5) and equations (T2-7) - (T2-9). Equation (T2-1) is the loglinearized version of the production function (6). Equation (T2-2) is the loglinearized version of the negative of the labor demand equation (7). Since we assume that government spending is equal to zero, consumption demand is equal to output demand:

$$
C=Y
$$

Therefore, wherever $C$ appears in the aggregate first order conditions for households we replace it with $Y$. When we follow this procedure, equation (31) yields equation (T2-3), the negative of the labor supply function; equation (32) yields equation (T24 ), the "aggregate demand function;" and equation (33) yields equation (T2-5), the money market equilibrium condition. The levels reaction function, equation (38), is rewritten as equation (T2-6), and the combination reaction function, equation (40), is rewritten as (T2-7). Equations (T2-8) and (T2-9) are inflation and money growth definitions, respectively. The equations in Table 2 contain the expected values of future shocks and endogenous variables, so they can be used to determine the equilibrium values for today's variables only after these expected values have been determined. We explain the determination of the expected values of future shocks and endogenous variables in Appendix A.

\section{The Model with Wage Stickiness}

In this section, we discuss the model with wage stickiness. We consider the levels model and the combination model separately. In both models notional labor supply is used in determining contract wages. For simplicity, we assume that notional labor supply is perfectly inelastic $(\chi \rightarrow \infty)$. Under this assumption, natural employment, the level of employment determined by the notional model given shocks is a constant, so it is easier to evaluate the relative performance of the alternative special cases of the reaction functions. 


\subsection{The Levels Reaction Function}

\subsubsection{The Full Levels Model}

The levels model with wage stickiness is obtained by assuming that there are oneperiod wage contracts and that prices are perfectly flexible. Today each household and all firms agree on a nominal wage for that household based on information available as of yesterday, and each household agrees to supply whatever amount of its labor firms want at its contract wage. The nominal wage for each household is set so that the marginal disutility of labor for that household is equal to the marginal value product of that household's labor. The notional labor supply schedule is used along with all the other equations of the notional levels model in setting the nominal wage, but it is omitted from the full levels model with wage stickiness.

In particular, today's nominal wage is determined by taking expectations of the notional levels model in Table 2 with $\chi \rightarrow \infty$ based on yesterday's information and setting the nominal wage equal to the expected nominal wage. With one-period wage contracts, i.i.d. shocks, and fulfillment of the conditions for a unique equilibrium in the levels model, it is shown in Appendix A that

$$
\begin{gathered}
y_{\mid-1}=l_{\mid-1}=x_{\mid-1}=w_{\mid-1}=p_{\mid-1}=U_{\mid-1}=m_{\mid-1}=i_{\mid-1}=v_{\mid-1}=0, \\
p_{+1 \mid-1}=y_{+1 \mid-1}=U_{+1 \mid-1}=0
\end{gathered}
$$

where the subscripts $\mid-1$ and $+1 \mid-1$ indicate, respectively, the expectation of a variable dated today based on yesterday's information and the expectation of a variable dated tomorrow based on yesterday's information. It follows that

$$
w=w_{\mid-1}=0
$$

The full levels model with wage stickiness is shown in Table 3. It is obtained by beginning with the notional levels model in Table 2, dropping the equation for notional labor supply, and making use of the information in (42) and (43). Whenever the notional labor supply function is left out of the model with nominal stickiness as it is in both the levels and combination models with both wage stickiness and wage and price stickiness, the solution of the model with nominal stickiness does not depend on the value of $\chi$.

Table 3: Full Levels Model with Wage Stickiness

$\begin{array}{lll}y=(1-\alpha) l+x & \text { production function } & \mathrm{T} 3-1 \\ p-w=\alpha l-x & \text { labor demand } & \mathrm{T} 3-2 \\ w=0 & \text { wage setting } & \mathrm{T} 3-3 \\ \sigma y=-(i+p)+U & \text { aggregate demand } & \mathrm{T} 3-4 \\ m=p+\phi y-\varepsilon i+v & \text { money market equilibrium } & \mathrm{T} 3-5 \\ i=\lambda_{m} m+\lambda_{y} y+\lambda_{p} p & \text { reaction function } & \mathrm{T} 3-6\end{array}$




\subsubsection{The Schedules and a Relation for the Levels Model}

The equations for the schedules and a relation used to analyze the levels model with wage stickiness are shown in Table 4 . Note that the first three equations determine the three variables $y, p$, and $i$ given values of the shocks. We explain the schedules using Figure 1, Panel A. The aggregate supply $(A S)$ schedule slopes upward because an increase in $p$ causes the real wage to fall, so employment and, therefore, output increase. Its equation (T4-1) is derived by adding equations (T3-2) and (T3-3) and using the resulting equation to eliminate $l$ from the production function (T3-1). Its slope is $\alpha /(1-\alpha)$. Note that $i$ does not enter the equation for the aggregate supply schedule.

Table 4: Schedules and Relation for Levels Model with Wage Stickiness

$$
\begin{array}{llr}
\alpha y=(1-\alpha) p+x & A S \text { schedule } & \mathrm{T} 4-1 \\
\sigma y=-(i+p)+U & A D \text { schedule } & \mathrm{T} 4-2 \\
i=\left(\frac{\lambda_{y}+\lambda_{m} \phi}{1+\lambda_{m} \varepsilon}\right) y+\left(\frac{\lambda_{p}+\lambda_{m}}{1+\lambda_{m} \varepsilon}\right) p+\left(\frac{\lambda_{m}}{1+\lambda_{m} \varepsilon}\right) v & R \text { schedule } & \mathrm{T} 4-3 \\
& & \\
p+y=0 & P Y \text { constant schedule } & \mathrm{T} 4-4 \\
p+y=l & P Y \text { to } L \text { relation } & \mathrm{T} 4-5
\end{array}
$$

The aggregate demand $(A D)$ schedule slopes downward because, given that the expected future price level is fixed in the levels model, an increase in $p$ raises the expected real interest rate thereby reducing $y$ demanded. ${ }^{21}$ Its equation (T4-2) is just the aggregate demand equation (T3-4), and its slope is $-\sigma$ where $\sigma$ must be greater than one under our assumptions. ${ }^{22}$ An increase in $i$ shifts the $A D$ schedule down by the amount of the increase, say from $A D$ to $A D_{1}$, because unit increases in $i$ and $p$ reduce demand by equal amounts.

The PY constant $(P Y)$ schedule shows the pairs of $p$ and $y$ for which nominal income is constant. Its equation is (T4-4). It has a slope of negative one.

The $P Y$ schedule has another interpretation in the levels model with wage stickiness. Adding equations (T3-1), (T3-2), and (T3-3) yields the PY to L relation (T4-5). According to this relation there is a one-to-one relationship between the change in nominal income, $p+y$, and the change in employment, $l .^{23}$ Therefore, the $P Y$ schedule also gives the pairs of $p$ and $y$ for which employment is constant.

\footnotetext{
${ }^{21}$ The assumptions underlying our $A D$ schedule and the textbook aggregate demand schedule are different. In deriving our schedule, it is assumed that the nominal interest rate is constant. However, in deriving the textbook aggregate demand schedule, it is assumed that the nominal interest rate moves in order to keep the money market in equilibrium given a fixed money supply. In algebraic terms, the nominal interest rate is eliminated from the aggregate demand equation (T3-4) using the money market equilibrium condition (T3-5).

${ }^{22}$ In general, $\sigma$ may be greater than or less than one. However, above we impose a restriction on the parameters in order to insure that $\delta=\sigma$ and $\zeta=0$, and this restriction can only be met if $\sigma>1$.

${ }^{23}$ In Henderson and McKibbin (1993a) it is shown that there is a one-to-one relationship between the changes in nominal income and employment no matter whether the elasticity of substitution between labor and another factor of production is equal to one or to some other constant.
} 
The reaction $(R)$ schedule slopes downward. Increases in both $p$ and $y$ raise the right hand side of the reaction function (T3-6), so in order to keep the right hand side constant, increases in $y$ must be matched by decreases in $p$. Increases in both of these variables raise the right hand of (T3-6) directly by equal amounts and indirectly by inducing increases in the money supply. The equation for $R,(\mathrm{~T} 4-3)$, is obtained by substituting equation (T3-5) into equation (T3-6) and solving for $i$. In the general case, the slope of $R$ is $0>-\frac{\lambda_{y}+\lambda_{m} \phi}{\lambda_{p}+\lambda_{m}}<-1$, and an increase in $i$ shifts $R$ up, say from $R_{0}$ to $R_{1}$. For a given value of $y$, an increase in $i$ raises the left hand side of the reaction function (T3-6) directly and lowers the right hand side indirectly because it reduces the money supply, so it must be matched by an increase in $p$ which raises the right hand side of (T3-6) both directly and indirectly through its effect on the money supply.

It is useful to explain what happens to the slope of the $R$ schedule and how much $R$ shifts with increases in $i$ in some important special cases shown in Figure 1, Panel C. With money stock targeting $(M T)$, we have $\lambda_{m} \rightarrow \infty$ and $\lambda_{y}$ and $\lambda_{p}$ finite, so the $R$ schedule represented by the $R_{m \& i}$ schedule has a slope of $-\phi$ and shifts up and to the right with increases in $i$. When we consider $M T$ we focus attention on the case in which $\phi<1$ so that the $R_{m \& i}$ schedule is flatter than the $A D$ schedule under our assumptions but call attention to the case in which $\phi>1$ in which it is possible for the $R_{m \& i}$ schedule to be steeper than the $A D$ schedule when the results are different. With "interest rate targeting (IT)" we have $\lambda_{p}, \lambda_{y}$, and $\lambda_{m} \rightarrow 0$, so the $R$ schedule may have any negative slope depending on the relative sizes of $\lambda_{y}$ and $\lambda_{p}$ and shifts up and to the right by ever increasing amounts with increases in $i$ as $\lambda_{y}$, $\lambda_{p}$, and $\lambda_{m}$ approach zero. For simplicity, when we consider IT we focus attention on the case in which $\lambda_{p}=\lambda_{y}=0$ and $\lambda_{m} \rightarrow 0$, so the $R$ schedule is represented by the $R_{m \& i}$ schedule. With $M T$, the $R_{m \& i}$ schedule shifts to the right by a well-defined amount for a given increase in $i$ as $\lambda_{m} \rightarrow \infty$, but with $I T$, the $R_{m \& i}$ schedule shifts to the right by ever increasing amounts for a given increase in $i$ as $\lambda_{m} \rightarrow 0$.

With price level targeting (PT), we have $\lambda_{p} \rightarrow \infty$ and $\lambda_{y}$ and $\lambda_{m}$ finite, so the $R$ schedule, represented by $R_{p}$, is horizontal and does not shift with increases in $i$. With output targeting in the levels case $(Y T L)$, we have $\lambda_{y} \rightarrow \infty$, and $\lambda_{p}$ and $\lambda_{m}$ finite, so the $R$ schedule represented by $R_{y}$ is vertical and does not shift with increases in $i$. With nominal income targeting $(P Y T)$, we have $\lambda_{p}=\lambda_{y} \rightarrow \infty$ and $\lambda_{m}$ finite, so the $R$ schedule represented by $R_{p y}$ has a slope of negative one and does not shift with increases in $i$.

We are now prepared to discuss the effects of money demand, goods demand, and productivity shocks under IT, MT, PT, YTL, and PYT. We will discuss the effects of these kinds of shocks under several other types of targeting in the subsection on the combination reaction function. For each kind of shock we rank the different types of targeting for three variables: the price level (and by implication inflation), income, and employment. As stated in the introduction, we say that a given type of targeting is "better" than some other type for a given kind of shock and a given variable if the deviation of the variable from its target value is less with the given type of targeting. Table 13 at the end of the paper is a summary of rankings of all types of targeting 
for all kinds of shocks.

\subsubsection{Money Demand Shocks}

For money demand shocks, IT, PT, YTL and PYT are equivalent, and $M T$ is worse for all variables. The result that for money demand shocks $I T$ is better than $M T$, a basic result in stabilization economics, was derived by Bailey (1962) and extended by Poole (1970). ${ }^{24}$ Under IT, PT, YTL, and PYT, the goods market is insulated from the money demand shock.

First we consider IT and $M T$ using Figure 2, Panel A1. Under IT and $M T$ an increase in $v$ shifts the $R_{m \& i}$ schedule down, say to $R_{m \& i, 1}$. An increase in $v$ tends to increase the money supply, so $p$ must be lower for given values of $y$ in order to keep $i$ from changing. At the original values of $p, y$, and $i$ corresponding to point $a$ there is upward pressure on $i$.

Under IT $\left(\gamma_{m} \rightarrow 0\right)$, very small increases in $i$ must be matched by very large increases in $y$ for a given value of $p$. With virtually no change in $i$, the $R_{m \& i}$ schedule shifts back virtually all the way to its initial position. The $A D$ schedule shifts down hardly at all, so the new equilibrium is at virtually the same point as the old one, point $a$. As a result, $i, y, p$, and, therefore, $p+y$ and $l$ remain virtually unchanged.

Under $M T\left(\lambda_{m} \rightarrow \infty\right)$, increases in $i$ must be matched by finite increases in $y$ for a given value of $p$. As $i$ is increased, $R_{m \& i}$ shifts up and $A D$ shifts down until they intersect somewhere on the marked part of the $A S_{0}$ schedule between points $a$ and $b$ and below the $P Y$ schedule. In the new equilibrium, $i$ is higher and $y, p$, and, therefore, $p+y$ and $l$ are lower. Since $y$ is lower, $i+p$, the expected real interest rate, must be higher in order to keep the goods market in equilibrium. The new equilibrium lies on a new $A D$ schedule (not shown) located below $A D_{0} \cdot i+p$ would be unchanged if the new equilibrium lay directly below point $a$. However, since the new equilibrium lies at the intersection of the new $A D$ schedule and $A S_{0}$, the fall in $p$ must be less than the rise in $i$.

Now we consider PT, YTL, and PYT using Figure 2, Panel A2. Under PT $\left(\lambda_{p} \rightarrow \infty\right), Y T L\left(\lambda_{y} \rightarrow \infty\right)$, and PYT $\left(\lambda_{p}=\lambda_{y} \rightarrow \infty\right)$, an increase in $v$ has virtually no effect on the $R_{p}, R_{y}$, and $R_{p y}$ schedules, respectively. There is virtually no shift in the $A D$ schedule. As a result, $i, y$, and $p$ and, therefore, $p+y$ and $l$ remain virtually unchanged.

\subsubsection{Goods Demand Shocks}

For goods demand shocks, PT, YTL, and PYT are equivalent and are all better than $M T$ which, in turn, is better than $I T$ for all variables. The result that for goods demand shocks $M T$ is better than $I T$, another basic result in stabilization

\footnotetext{
${ }^{24}$ Poole (1970) extended Bailey (1962) by deriving the familiar "combination policy." Poole's analysis is one of the first applications of filtering in macroeconomics. He assumes that the policymaker observes the interest rate and the money supply but not output and uses the limited information about the shocks that have hit the economy that is conveyed by the interest rate and the money supply to form estimates of these shocks. The policymaker then acts to offset the effects of the estimated shocks on output.
} 
economics, was also derived by Bailey (1962) and extended by Poole (1970). Under $M T$, induced movements in the real interest rate offset some of the effects of the shocks on the goods market.

An increase in the demand for goods, an increase in $U$, causes the $A D$ schedule to shift up from $A D_{0}$ to $A D_{1}$ in Figure 2, Panels B1 and B2. Since an increase in $U$ increases the demand for goods, for a given value of $p, y$ must be higher in order to keep the goods market in equilibrium.

First we consider $I T$ and $M T$ using Figure 2, Panel B1. At point $b$ where the $A D_{1}$ and $A S_{0}$ schedules intersect, the $p, y$ pair is above $R_{m \& i}$, so there is upward pressure on $i$.

Under IT, with virtually no change in $i$, the $R$ schedule shifts virtually all the way to the intersection of the $A D_{1}$ and $A S$ schedules at point $b$, and the $A D$ schedule shifts down from $A D_{1}$ hardly at all. Therefore, the new equilibrium is arbitrarily close to the intersection of the $A D_{1}$ and $A S$ schedules at point $b$ which is above the $P Y$ schedule. In the new equilibrium, $p, y$, and, therefore, $p+y$, and $l$ are all higher. Since $i$ remains virtually constant, the increase in $y$ and the associated increase in $p$ must be large enough to almost fully offset the effect of the shock on the goods market. $m$ must rise by enough to satisfy money demand at an unchanged $i$ and higher $p$ and $y$.

Under $M T$, as $i$ is increased, the $R_{m \& i}$ schedule shifts up and the $A D$ schedule shifts down until they intersect somewhere on the marked part of the $A S$ schedule between points $a$ and $b$ and above the $P Y$ schedule. In the new equilibrium, $i, y$, $p$, and, therefore, $p+y$ and $l$ are all higher. For the money market to remain in equilibrium at an unchanged value of $m, p$ and $y$ must be higher given that $i$ is higher. However, the increases in all the variables except $i$ are smaller under $M T$ than under IT because smaller increases in $p$ and $y$ are required to reequilibrate the goods markets when $i$ is increased.

Now we consider PT, YTL, and PYT using Figure 2, Panel B2. Under PT, YTL, and $P Y T$, the new equilibrium is at the same point as the initial equilibrium, point $a$. In order to keep $p, y$, or $p+y$ constant, $i$ must be increased by enough to shift the $A D$ schedule virtually all the way back to its original position since increases in $i$ have virtually no effect on the $R_{p}, R_{y}$, and $R_{p y}$ schedules, respectively. In all three cases, $p, y, p+y$, and $l$ remain unchanged. The increase in $i$ must be larger under $P T, Y T L$, and PYT than under the $M T$ because $p, y$, and $p+y$ rise under the $M T$.

\subsubsection{Productivity Shocks}

With productivity shocks, for employment, $P Y T$ is better than all other types of targeting except in one special case in which it is the same as $M T$, and $I T \succ Y T L$. For the price level, $P T$ is better than all other kinds of targeting, and $P T \succ P Y T \succ$ $I T \succ Y T L$. For output, $Y T L$ is better than all other kinds of targeting, and $Y T L$ $\succ I T \succ P Y T \succ P T$. All other rankings depend on parameter values. Throughout most of this subsection we retain our assumption that the slope of the $R_{m \& i}$ schedule is less than one in absolute value, but we relax this assumption at the end of the subsection. 
An increase in productivity, an increase in $x$, causes the $A S$ schedule to shift down from $A S_{0}$ to $A S_{1}$ in Figure 2, Panels $\mathrm{C} 1$ and $\mathrm{C} 2$. In order to keep $y$ constant, $p$ must be lower so that $l$ will fall by enough to offset the effect of the increase in $x$. The pair of $y$ and $p$ that clears the goods market is given by the intersection of the $A S_{1}$ and the $A D$ schedules at point $b$.

First we consider IT and $M T$ using Figure 2, Panel C1. Since the $A D$ schedule is steeper than the $R_{m \& i}$ schedule, point $b$ lies below $R_{m \& i}$, so there is downward pressure on $i$. Under $I T$, with virtually no change in $i$, the $R_{m \& i}$ schedule shifts virtually all the way to the intersection of the $A S_{1}$ and $A D$ schedules at point $b$, and the $A D$ schedule shifts up hardly at all, so the new equilibrium is arbitrarily close to the intersection of the $A S_{1}$ and $A D$ schedules at point $b . y$ rises, and $p$ falls. The new equilibrium lies below the $P Y$ schedule, so $p+y$ and, therefore, $l$ must fall.

The conclusion that increases in productivity decrease employment may seem counterintuitive, but it can be explained. The pair of $y$ and $p$ consistent with unchanged factor use following the productivity shock is given by the intersection of the $A S_{1}$ and $P Y$ schedules at point $d$. This pair implies an excess supply of goods at an unchanged value of $i$. That is, in equilibrium $y$ must rise by less and $p$ must fall by more than the amounts consistent with unchanged factor use, so $l$ must fall.

Under $M T$, the $A D$ schedule shifts up and the $R$ schedule shifts down until they meet somewhere on the marked part of the $A S_{1}$ schedule between points $b$ and $c$. Since $i$ is decreased, $y$ rises by more, $p$ falls by less than under the IT. The new equilibrium may lie below or above the $P Y$ schedule, so employment may fall or rise, and if it rises the increase may be greater or less than the absolute value of the fall under $I T$.

Now we consider PT, YTL, and PYT using Figure 2, Panel C2. Under PT, YTL, and $P Y T$, the equilibria are at the intersections of the $R_{p}, R_{y}$, and $R_{p y}$ schedules with the $A S_{1}$ schedule at points e, f, and d, respectively. The $R_{p y}$ schedule coincides with the $P Y$ schedule, so the new equilibrium must be on the $P Y$ schedule just as the initial equilibrium is. $i$ is adjusted so that the $A D$ schedule passes through the intersection of the $A S_{1}$ and $P Y$ schedules at point $d$. Since the new equilibrium is on the $P Y$ schedule, employment is unchanged, so $P Y T$ is at least as good as every other kind of targeting for employment. Since employment is unchanged, $y$ falls and $p$ rises by amounts that are equal in absolute value to the increase in $x$. It is important to observe that the equilibrium increase in $y$ is the same as the increase in $y$ that would take place if wages were flexible and all markets cleared. ${ }^{25}$ Since the $A D$ schedule is steeper than the $R_{p y}$ schedule, $y$ rises by more, and $p$ falls by less under PYT than under IT. The $R_{p y}$ schedule has a slope of negative one, so if it were drawn in on Figure 2, Panel $\mathrm{C}$ it would be steeper than the $R_{m \& i}$ schedule and would cut the marked part of the $A S_{1}$ schedule. Therefore, the ranking of PYT and $M T$ for the

\footnotetext{
${ }^{25}$ Under our assumption that $\chi \rightarrow \infty$, the outcomes for all variables if wages are sticky are the same as they would be if wages were flexible when the simple sum $p+y$ is targeted, that is, with $P Y T$. Under the alternative assumption that $\chi$ remains finite, the outcomes for all variables if wages are sticky are the same as they would be if wages were flexible when the weighted sum $p+\left(\frac{\chi}{\chi+1}\right) y$ is targeted as shown by Koenig (1996).
} 
price level and output is ambiguous. PYT is better than $M T$ for employment except in the special case in which they are exactly the same.

$P T$ is better for the price level and worse for output than any other kind of targeting. Under $P T$, employment increases because the equilibrium is above the $P Y$ schedule, so PT is worse for employment than PYT. YTL is worse for the price level and better for output than any other kind of targeting. Under $Y T L$, employment falls because the equilibrium is below the $P Y$ schedule, so $Y T L$ is worse for employment than $P Y T$. Furthermore, the $P Y$ schedule (not shown) that passes through the $Y T L$ equilibrium is further from $P Y_{0}$ than the $P Y$ schedule (not shown) that passes through the $I T$ equilibrium, so $Y T L$ is worse for employment than $I T$. The size of the shift of the $A S$ curve along the $P Y$ schedule depends only on the size of the productivity shock and not on the slope of the $A S$ schedule. Changing the slope of the $A S$ schedule causes it to rotate around a point on the $P Y$ schedule. If $\alpha=1 / 2$ so that the slope of the aggregate supply curve is unity, the absolute values of the changes of employment are the same under PT and $Y T L$. If $\alpha>1 / 2$ so that the slope of the $A S$ schedule is greater than unity, $P T$ is better than $Y T L$ for employment and vice versa. The ranking of $M T$ relative to $P T$ and $Y T L$ depends on parameter values.

So far we have been assuming that the slope of the $R_{m \& i}$ schedule is less than one in absolute value. The following additional results can be proved for cases in which

the slope of the $R_{m \& i}$ is greater than one in absolute value. For employment, PYT is better than all other kinds of targeting and the ranking of all other kinds of targeting depends on parameters. For the price level, $P T$ is preferred to all other kinds of targeting and $P T \succ P Y T \succ I T, M T \succ Y T L$, but the ranking of $I T$ and $M T$ depends on parameters. For output, YTL $\succ I T, M T \succ P Y T \succ P T$ and whether IT or $M T$ is preferred depends on parameters.

\subsection{The Combination Reaction Function}

\subsubsection{The Full Combination Model}

The combination model with wage stickiness is also obtained by assuming that there are one-period wage contracts. In particular, today's nominal wage is determined by taking expectations of the notional combination model in Table 2 with $\chi \rightarrow \infty$ based on yesterday's information. With one-period wage contracts, i.i.d. shocks, and fulfillment of the conditions for a unique equilibrium in the combination model, it is shown in Appendix A that

$$
\begin{gathered}
y_{\mid-1}=l_{\mid-1}=x_{\mid-1}=U_{\mid-1}=i_{\mid-1}=v_{\mid-1}=\pi_{+1 \mid-1}=y_{+1 \mid-1}=U_{+1 \mid-1}=0, \\
w_{\mid-1}=p_{\mid-1}=\pi_{\mid-1}+p_{-1}, \\
\pi_{\mid-1}=\frac{\gamma_{\mu}}{\gamma_{\pi}+\gamma_{\mu}}\left(\phi y_{-1}-\varepsilon i_{-1}+v_{-1}\right)=\frac{\gamma_{\mu}}{\gamma_{\pi}+\gamma_{\mu}}\left(m_{-1}-p_{-1}\right),
\end{gathered}
$$

and also that

$$
\pi_{+1 \mid}=\frac{\gamma_{\mu}}{\gamma_{\pi}+\gamma_{\mu}}(\phi y-\varepsilon i+v)
$$


It follows that

$$
w=w_{\mid-1}=p_{\mid-1}=\pi_{\mid-1}+p_{-1} .
$$

The full combination model with wage stickiness is shown in Table 5. It is obtained by beginning with the notional combination model in Table 2, dropping the equation for notional labor supply, and making use of the information in equations (44), (45), and (46)

Table 5: Full Combination Model with Wage Stickiness

$\begin{array}{llr}y=(1-\alpha) l+x & \text { production function } & \mathrm{T} 5-1 \\ p-w=\alpha l-x & \text { labor demand } & \mathrm{T} 5-2 \\ w-p_{-1}=\pi_{-1} & \text { wage setting } & \mathrm{T} 5-3 \\ \sigma y=-\left[i-\frac{\gamma_{\mu}}{\gamma_{\pi}+\gamma_{\mu}}(\phi y-\varepsilon i+v)\right]+U & \text { aggregate demand } & \mathrm{T} 5-4 \\ m=p+\phi y-\varepsilon i+v & \text { money market equilibrium } & \mathrm{T} 5-5 \\ i=\gamma_{\mu} \mu+\gamma_{y} y+\gamma_{\pi} \pi & \text { reaction function } & \mathrm{T} 5-6 \\ \pi=p-p_{-1} & \text { inflation definition } & \mathrm{T} 5-7 \\ \mu=m-m_{-1} & \text { money growth definition } & \mathrm{T} 5-8\end{array}$

\subsubsection{The Schedules and a Relation for the Combination Model}

The equations for the schedules and a relation used to analyze the combination model with wage stickiness are shown in Table 6. We explain the schedules using Figure 1, Panel B.

The aggregate supply $(A S)$ schedule slopes upward because an increase in $\pi$ causes the real wage to fall, so employment and, therefore, output increase. Its equation (T61 ) is derived by adding equations (T5-1) and (T5-2), making use of equation (T5-7), and using the resulting equation to eliminate $l$ from the production function (T5-1). Its slope is $\alpha /(1-\alpha)$. It is the same as the $A S$ schedule for the levels model with wage stickiness in all essential respects because yesterday's price is given so all the movements in $\pi$ are generated by movements in $p$.

Table 6: Schedules and Relation for Combination Model with Wage Stickiness

$$
\begin{array}{llr}
\alpha y=(1-\alpha)\left(\pi-\pi_{\mid-1}\right)+x & A S \text { schedule } & \text { T6-1 } \\
\left(\sigma-\frac{\gamma_{\mu} \phi}{\gamma_{\pi}+\gamma_{\mu}}\right) y=-\left(1+\frac{\gamma_{\mu} \varepsilon}{\gamma_{\pi}+\gamma_{\mu}}\right) i+U+\frac{\gamma_{\mu}}{\gamma_{\pi}+\gamma_{\mu}} v & A D \text { schedule } & \text { T6-2 } \\
i=\frac{\gamma_{y}+\gamma_{\mu} \phi}{1+\gamma_{\mu} \varepsilon} y+\frac{\gamma_{\pi}+\gamma_{\mu}}{1+\gamma_{\mu} \varepsilon} \pi+\frac{\gamma_{\mu}}{1+\gamma_{\mu} \varepsilon} v-\frac{\gamma_{\pi}+\gamma_{\mu}}{1+\gamma_{\mu} \varepsilon} \pi_{\mid-1} & R \text { schedule } & \mathrm{T} 6-3 \\
\pi+y=0 & \Pi Y \text { constant schedule } & \mathrm{T} 6-4 \\
\pi+y=l+\pi_{\mid-1} & \Pi Y \text { to } L \text { relation } & \mathrm{T} 6-5
\end{array}
$$

The aggregate demand $(A D)$ schedule is vertical because aggregate demand does not depend on the rate of inflation between yesterday and today either directly or indirectly through the expected rate of inflation between today and tomorrow. Its 
equation, (T6-2), is just a rearranged version of the aggregate demand equation (T54). Today's values of $y, i$, and $U$ affect aggregate demand directly, and, as long as $\gamma_{\mu}>0$, today's values of $y, i$, and $v$ affect aggregate demand indirectly through the expected rate of inflation. An increase in the nominal interest rate raises the real interest rate directly and also indirectly because it lowers the expected rate of inflation. An increase in output lowers the marginal utility of consumption today, but it also lowers the real interest rate by increasing the expected rate of inflation. That is, the coefficient on output in the equation for the $A D$ schedule, $\sigma-\frac{\gamma_{\mu} \phi}{\gamma_{\pi}+\gamma_{\mu}}$, may in principle be either positive or negative since $\frac{\gamma_{\mu}}{\gamma_{\pi}+\gamma_{\mu}}<1$ and under our assumptions $\sigma>1$ and $\phi \geq 1$. For simplicity, we focus on the case in which $\sigma-\frac{\gamma_{\mu} \phi}{\gamma_{\pi}+\gamma_{\mu}}>0$. In this case, an increase in $i$ shifts $A D$ to the left, say from $A D_{0}$ to $A D_{1}$, because an increase in the interest rate reduces the amount of output demanded.

The inflation plus output ( $\Pi Y$ ) constant schedule shows the pairs of $\pi$ and $y$ for which inflation plus output is constant. Its equation is (T6-4). It has a slope of negative one.

The $\Pi Y$ schedule has another interpretation in the combination model with wage stickiness. Adding equations (T5-1), (T5-2), and (T5-3) yields the inflation plus output to employment ( $\Pi Y$ to $L$ ) relation (T6-5). According to this relation there is a one-to-one relationship between the change in inflation plus output, $\pi+y$, and the change in employment, $l$. Therefore, the $\Pi Y$ schedule also gives the pairs of $\pi$ and $y$ for which employment is constant.

The reaction $(R)$ schedule slopes downward because increases in both $\pi$ and $y$ raise the right hand side of (T5-6) both directly and indirectly by inducing increases in money growth, so in order to keep the right hand side constant, increases in $y$ must be matched by decreases in $\pi$. The equation for $R$, (T6-3), is obtained by differencing (T5-5), making use of equation (T5-7) and the expression for $\pi_{\mid-1}$ in equation (44), substituting that result into equation (T5-8), substituting that result into (T5-6), and solving for $i$. The slope of $R$ is $0>-\frac{\gamma_{y}+\gamma_{\mu} \phi}{\gamma_{\pi}+\gamma_{\mu}} \geq-1$. An increase in $i$ shifts $R$ up, say from $R_{0}$ to $R_{1}$. For a given value of $y$, an increase in $i$ raises the left hand side of the reaction function (T5-6) directly and lowers the right hand side indirectly because it reduces money growth, so it must be matched by an increase in $\pi$ which raises the right hand side of (T5-6) both directly and indirectly through its effect on money growth.

It is helpful to explain what happens to the slope of $R$ and how much $R$ shifts with increases in $i$ in some important special cases using Figure 1, Panel D. With money growth targeting $(\mathcal{M T}), \gamma_{\mu} \rightarrow \infty$, so the $R$ schedule has a slope of $-\phi$ and shifts up and to the right with increases in $i$. With the combination reaction function, there is no sensible limiting case that can be thought of as "interest rate targeting." For uniqueness it is necessary to have $\gamma_{\pi}+\gamma_{\mu}>1$, so $\gamma_{\pi}$ and $\gamma_{\mu}$ cannot both approach zero. With inflation targeting $(\Pi T), \gamma_{\pi} \rightarrow \infty$, so $R$ is horizontal and does not shift with increases in $i$; with output targeting in the combination case $(Y T C), \gamma_{y} \rightarrow \infty$, so $R$ is vertical and does not shift with increases in $i$; with inflation plus output targeting $(\Pi Y T), \gamma_{\pi}=\gamma_{y} \rightarrow \infty$, so $R$ has a slope of negative one and does not shift 
with increases in $i$.

\subsubsection{Money Demand Shocks}

With money demand shocks, the results for $\Pi T, Y T C, \Pi Y T$, and $\mathcal{M T}$ in the combination model are the same as the results for PT, YTL, PYT, and MT in the levels model, respectively. $\Pi T, Y T C$, and $\Pi Y T$ are equivalent and are all better than $\mathcal{M}$ for all variables. Under $\Pi T, Y T C$, and $\Pi Y T$, the goods market is completely insulated from the money demand shock.

Under $\mathcal{M T}$ (Figure 3, Panel A1), an increase in $v$ shifts the $R_{\mu}$ schedule down say to $R_{\mu, 1}$. As $i$ is increased to prevent an increase in money growth, $R_{\mu}$ shifts up and $A D$ shifts left until they intersect somewhere on the marked part of the $A S$ schedule between points $a$ and $b$ and below the $\Pi Y$ schedule. In the new equilibrium, $i$ is higher and $y, \pi$, and, therefore, $\pi+y$ and $l$ are lower.

Under $\Pi T, Y T C$, and $\Pi Y T$ (Figure 3, Panel A2), an increase in $v$ has virtually no effect on the $R_{\pi}, R_{y}$, and $R_{\pi y}$ schedules, respectively. There is virtually no shift in the $A D$ schedule. As a result, $i, y, \pi$, and, therefore, $\pi+y$ and $l$ remain virtually unchanged.

\subsubsection{Goods Demand Shocks}

For goods demand shocks as for money demand shocks, the results for ПT, YTC, $\Pi Y T$, and $\mathcal{M} T$ in the combination model are the same as the results for $P T, Y T L$, $P Y T$, and $M T$ in the levels model, respectively. $\Pi T, Y T C$, and $\Pi Y T$ are equivalent and are all better than $\mathcal{M T}$ for all variables.

An increase in the demand for goods, an increase in $U$, causes the $A D$ schedule to shift to the right from $A D_{0}$ to $A D_{1}$ in Figure 3, Panels B1 and B2. Under $\mathcal{M} T$ (Figure 3, Panel B1), $i$ is increased in order to prevent an increase in the money growth rate. As $i$ is increased, the $R_{\mu}$ schedule shifts up and $A D$ schedule shifts left until they intersect somewhere on the marked part of the $A S$ schedule between points $a$ and $b$ and above the $\Pi Y$ schedule. In the new equilibrium, $i, y, \pi$, and, therefore, $\pi+y$ and $l$ are all higher.

Under $\Pi T, Y T C$, and $\Pi Y T$ (Figure 3, Panel B2), the new equilibrium is at the same point as the initial equilibrium, point $a$. In order to keep $\pi, y$, or $\pi+y$ constant, $i$ must be increased by enough to shift the $A D$ schedule virtually all the way back to its original position since increases in $i$ have virtually no effect on the $R_{\pi}, R_{y}$, and $R_{\pi y}$ schedules, respectively. In all three cases, $\pi, y, \pi+y$, and $l$ remain unchanged.

\subsubsection{Productivity Shocks}

With productivity shocks, the results for $\Pi T$ and $\mathcal{M} T$ in the combination model are the same as the results for $P T$ and $M T$, respectively, in the levels model for all variables, and the results for $Y T C$ and $\Pi Y T$ in the combination model are the same as the results for $Y T L$ and $P Y T$ in the levels model, respectively, for all variables

except the nominal interest rate and expected inflation. For employment, $\Pi Y T$ is better than all other types of targeting except in one special case in which it is the 
same as $\mathcal{M}$. For inflation, $\Pi T$ is better than all other kinds of targeting, and $\Pi T$ $\succ \Pi Y T \succ Y T C$. For output, $Y T C$ is better than all other kinds of targeting, and $Y T C \succ \Pi Y T \succ \Pi T$. All other rankings depend on parameter values. Throughout this subsection we restrict attention to the case in which the slope of the $R_{\mu}$ schedule is less than one in absolute value. ${ }^{26}$

An increase in productivity, an increase in $x$, causes the $A S$ schedule to shift down from $A S_{0}$ to $A S_{1}$ in Figure 3, Panels $\mathrm{C} 1$ and $\mathrm{C} 2$. Under $\mathcal{M} T$ (Figure 3, Panel $\mathrm{C} 1$ ), point $b$ lies below $R_{\mu}$ since the $A D$ schedule is vertical, so there is downward pressure on $i$. The $A D$ schedule shifts right and the $R_{\mu}$ schedule shifts down until they meet somewhere on the marked part of the $A S_{1}$ schedule between points $b$ and $c$. The new equilibrium may lie below or above the $\Pi Y$ schedule, so employment may fall or rise.

Under $\Pi T, Y T C$, and $\Pi Y T$ (Figure 3, Panel C2), the equilibria are at the intersections of the $R_{\pi}, R_{y}$, and $R_{\pi y}$ schedules with the $A S_{1}$ schedule at points e, $\mathrm{f}$, and $\mathrm{d}$, respectively. The $R_{\pi y}$ schedule coincides with the $\Pi Y$ schedule, so the new equilibrium must lie on the $\Pi Y$ schedule just as the initial equilibrium does. $i$ is adjusted so that the $A D$ schedule passes through the intersection of the $A S_{1}$ and $\Pi Y$ schedules at point $d$. Since the new equilibrium is on the $\Pi Y$ schedule, employment is unchanged, so $\Pi Y T$ is at least as good as every other kind of targeting for employment. Since employment is unchanged, $y$ falls and $\pi$ rises by amounts that are equal in absolute value to the increase in $x$. The $R_{\pi y}$ schedule has a slope of negative one, so if it were drawn in on Figure 3, Panel C1, it would cut the marked part of the $A S_{1}$ schedule. Therefore, the ranking of $\Pi Y T$ and $\mathcal{M T}$ for the price level and output is ambiguous. $\Pi Y T$ is better than $\mathcal{M} T$ for employment except in the special case in which they are exactly the same.

$\Pi T$ is better for the price level and worse for output than any other kind of targeting. Under $\Pi T$, employment increases because the equilibrium is above the $\Pi Y$ schedule, so $\Pi T$ is worse for employment than $\Pi Y T$. $Y T C$ is worse for the price level and better for output than any other kind of targeting. Under $Y T C$, employment falls because the equilibrium is below the $\Pi Y$, so $Y T C$ is worse for employment than $\Pi Y T$. For employments, the ranking of $\mathcal{M T}$, $\Pi$ T, and $Y T C$ depends on parameter values.

\subsubsection{The Price Level in the Levels Model and the Combination Model}

There is an important difference between the levels model and the combination model. In the levels model today's shocks do not affect the expected future price level, but in the combination model they do.

As an illustration of this difference, we compare the effects on the expected future price level of a positive productivity shock with $P Y T$ in the levels model to those with $\Pi Y T$ in the combination model. The price level falls by the same amount with $P Y T$ and $\Pi Y T$. With PYT, agents expect that tomorrow the monetary authority will restore the price level to its target level, so the expected rate of inflation is positive,

\footnotetext{
${ }^{26}$ Changes in assumption about the slope of $R_{\mu}$ in the combination model have the same implications for the effects on variables as the analogous changes in assumption about the slope of $R_{m \& i}$ in the levels model for all variables except the nominal interest rate and expected inflation.
} 
but with $\Pi Y T$, they expect that tomorrow the monetary authority will leave the price level at the actual value realized today so that the rate of inflation will be at

its target value of zero. Since expected rates of inflation are different under the two types of targeting so are nominal interest rates. Therefore, $i$ falls by less with $P Y T$ than with $\Pi Y T$ because it does not have to fall by the full amount necessary to lower the expected real interest rate by the required amount. If there were no further disturbances after today, the price level would be at its unchanged target value from tomorrow on with PYT but would be permanently lower with ПYT.

In general, in the levels model the expected value of the price level at any time in the future based on today's information is independent of today's shocks and the values of variables in all previous periods. That is, it follows from equation (42) that

$$
p_{t+k \mid t}=0, \quad k=1, \ldots, \infty .
$$

However, in the combination model the expected value of the price level at any time in the future based on today's information depends on today's shocks and lagged values of the price level and the money supply. That is, it follows from equations (44) and (45) and the solutions for $y_{t} \pi_{t}$, and $i_{t}$ in Appendix B that

$$
\begin{aligned}
p_{t+k \mid t}= & p_{t-1}+\sum_{i=t}^{t+k} \pi_{i \mid t}=p_{t-1}+\pi_{t}+\frac{\gamma_{\mu}}{\gamma_{\pi}+\gamma_{\mu}}\left(\phi y_{t}-\varepsilon i_{t}+v_{t}\right) \\
= & \left\{1-\gamma_{\mu} \Delta_{W, C}^{-1}\left[\alpha\left(J+\gamma_{\mu} \varepsilon\right)+\gamma_{\mu} \xi(\phi+\varepsilon \sigma)\right]\right\} p_{t-1} \\
& +\gamma_{\mu} \Delta_{W, C}^{-1}\left[\alpha\left(J+\gamma_{\mu} \varepsilon\right)+\gamma_{\mu} \xi(\phi+\varepsilon \sigma)\right] m_{t-1} \\
& +\Delta_{W, C}^{-1}\left(\alpha+\xi\left(\sigma+\gamma_{y}\right)\right) \gamma_{\mu} v_{t}+\Delta_{W, C}^{-1}\left(J \alpha+\xi \gamma_{\mu}\left(\phi-\varepsilon \gamma_{y}\right)\right) U_{t} \\
& +\Delta_{W, C}^{-1}\left(\gamma_{\mu}\left(\phi-\varepsilon \gamma_{y}\right)-J(\sigma+1)\right) x_{t}, \quad k=1, \ldots, \infty
\end{aligned}
$$

where

$$
\begin{gathered}
\Delta_{W, C}=\alpha J\left(J+\gamma_{\mu} \varepsilon\right)+(1-\alpha)\left[(J-1) \gamma_{\mu} \phi+J\left(1+\gamma_{\mu} \varepsilon\right) \sigma+\left(J+\gamma_{\mu} \varepsilon\right) \gamma_{y}\right], \\
J=\gamma_{\mu}+\gamma_{\pi}>1 .
\end{gathered}
$$

\section{The Model with Wage and Price Stickiness}

\subsection{The Levels Reaction Function}

\subsubsection{The Full Levels Model}

The levels model with wage and price stickiness is obtained by assuming that there are both one-period wage contracts and one-period price contracts. One-period wage contracts are described in the previous section, so we describe only one-period price 
contracts here. Each firm and all households agree on today's price for that firm's output based on information available as of yesterday, and each firm agrees to supply whatever amount of its output households want at its contract price. The price for each firm is set so that the marginal value product for that firm is equal to the real wage for a bundle of labor made up of an equal amount of labor from each household. The equations for both notional labor demand and notional labor supply are used along with all the other equations of the notional levels model in setting the contract wage and contract price, but both equations are omitted from the full levels model with wage and price stickiness. ${ }^{27}$

In particular, today's nominal wage and price are determined by taking expectations of the notional levels model in Table 2 with $\chi \rightarrow \infty$ based on yesterday's information and setting the nominal wage equal to the expected nominal wage and the price equal to the expected price. It follows from the discussion of the levels model with only wage stickiness that

$$
\begin{aligned}
& w=w_{\mid-1}=0, \\
& p=p_{\mid-1}=0 .
\end{aligned}
$$

The full levels model with wage and price stickiness is shown in Table 7 . It is obtained by beginning with the notional levels model in Table 2, dropping the equations for notional labor supply and notional labor demand, and making use of the information in (42), (50), and (51).

Table 7: Full Levels Model with Wage and Price Stickiness

$$
\begin{array}{lll}
y=(1-\alpha) l+x & \text { production function } & \mathrm{T} 7-1 \\
p=0 & \text { price setting } & \mathrm{T} 7-2 \\
w=0 & \text { wage setting } & \mathrm{T} 7-3 \\
\sigma y=-(i+p)+U & \text { aggregate demand } & \mathrm{T} 7-4 \\
m=p+\phi y-\varepsilon i+v & \text { money market equilibrium } & \mathrm{T} 7-5 \\
i=\lambda_{m} m+\lambda_{y} y+\lambda_{p} p & \text { reaction function } & \mathrm{T} 7-6
\end{array}
$$

\subsubsection{The Schedules and a Relation for the Levels Model}

The equations for the schedules and a relation used to analyze the levels model with wage and price stickiness are shown in Table 8, and the schedules are plotted in $p, y$ space in Figure 1, Panel E.

The aggregate supply schedule and the nominal income-employment relation in the levels model with wage and price stickiness are different from those in the levels

\footnotetext{
${ }^{27}$ If labor were not the only costlessly adjustable factor of production, the assumption of price stickiness would not imply leaving the real wage and the aggregate marginal product of labor entirely out of account. For example, if the model included costlessly adjustable capital as well as costlessly adjustable labor, and if the production function were constant returns to scale, the capital-labor ratio would be determined by the condition that the wage-rental ratio equal the ratio of the marginal product of labor to the marginal product of capital, and firms would use the production function to determine the amounts of both factors necessary to satisfy demand at the fixed price.
} 
model with wage stickiness considered in the previous section, but the other three relationships in Table 8 are identical to the corresponding relationships in Table 4. $A S$ in the levels model with wage and price stickiness is horizontal because firms agree to produce any amount demanded at the price fixed in the one-period contract. Its equation, (T8-1), is identical to the price setting equation (T7-2). The nominal income-employment relation, (T8-5), in the levels model with wage and price stickiness is obtained by adding equations (T7-1) and (T7-2). If there is a productivity shock, there is not a one-to-one relationship between the change in nominal income and the change in employment.

Table 8: Schedules and Relation for Levels Model with Wage and Price Stickiness

$$
\begin{array}{lll}
p=0 & A S \text { schedule } & \mathrm{T} 8-1 \\
\sigma y=-(i+p)+U & A D \text { schedule } & \mathrm{T} 8-2 \\
i=\left(\frac{\lambda_{y}+\lambda_{m} \phi}{1+\lambda_{m} \varepsilon}\right) y+\left(\frac{\lambda_{p}+\lambda_{m}}{1+\lambda_{m} \varepsilon}\right) p+\left(\frac{\lambda_{m}}{1+\lambda_{m} \varepsilon}\right) v & R \text { schedule } & \mathrm{T} 8-3 \\
& & \\
p+y=0 & P Y \text { constant schedule } & \mathrm{T} 8-4 \\
p+y=(1-\alpha) l+x & P Y \text { to } L \text { relation } & \mathrm{T} 8-5
\end{array}
$$

\subsubsection{Money Demand Shocks}

With both wage and price stickiness, just as with only wage stickiness, for money demand shocks, IT, PT, YTL, and PYT are equivalent, and $M T$ is worse for all variables because under $I T, P T, Y T L$, and $P Y T$ money demand shocks do not cause the interest rate to change, but under $M T$ they do.

Under IT and $M T$ (Figure 4, Panel A1) an increase in $v$ shifts the $R_{m \& i}$ schedule down say to $R_{m \& i, 1}$, and there is upward pressure on $i$. Under $I T$, the $R_{m \& i}$ schedule shifts back virtually all the way to its initial position, and the $A D$ schedule shifts down hardly at all, so the new equilibrium is at virtually the same point as the old one, point $a$, so $i, y, p$, and, therefore, $p+y$ and $l$ remain virtually unchanged. Under $M T, R_{m \& i}$ shifts up and $A D$ shifts down until they intersect somewhere on the marked part of the $A S$ schedule between points $a$ and $b$ and below the $P Y$ schedule. In the new equilibrium, $i$ is higher and $y, p$, and, therefore, $p+y$ and $l$ are lower.

Under PT, YTL, and PYT (Figure 4, Panel A2), an increase in $v$ has virtually no effect on the $R_{p}, R_{y}$, and $R_{p y}$ schedules, respectively. There is virtually no shift in the $A D$ schedule. As a result, $i, y$, and $p$ and, therefore, $p+y$ and $l$ remain virtually unchanged.

\subsubsection{Goods Demand Shocks}

With both wage and price stickiness, just as with only wage stickiness, for goods demand shocks, PT, YTL, and PYT are better than MT which is better than $I T$ for all variables. An increase in the demand for goods, an increase in $U$, causes the $A D$ schedule to shift up from $A D_{0}$ to $A D_{1}$ in Figure 4, Panels B1 and B2.

First we consider $I T$ and $M T$ using Figure 4, Panel B1. Under IT, $i$ remains virtually unchanged, so the new equilibrium is arbitrarily close to the intersection of 
the $A D_{1}$ and $A S$ schedules at point $b$ which is above the $P Y$ schedule. In the new equilibrium, $p, y$, and, therefore, $p+y$, and $l$ are all higher. Under $M T, i$ is increased in order to prevent an increase in $m$. The new equilibrium lies on the marked part of the $A S$ schedule between points $a$ and $b$ and above the $P Y$ schedule. $p$ is unchanged, but $i, y$, and, therefore, $p+y$, and $l$ are all higher. However, the increases in all the variables but $i$ are smaller under $M T$ than under $I T$ because smaller increases in $y$ are required to reequilibrate the goods markets when $i$ is increased.

Now we consider PT, YTL, and PYT using Figure 4, Panel B2. Under PT, $Y T L$, and $P Y T$, the new equilibrium is at the same point as the initial equilibrium, point $a$ on the $P Y$ schedule. In order to keep $p+y$ constant, $i$ must be increased by enough to shift the $A D$ schedule all the way back to its original position. Since $p$ is fixed, stabilizing $p+y$ and, therefore, $l$ is equivalent to stabilizing $y$. The increase in $i$ must be larger under PT, YTL, and PYT than under $M T$ because $y$ rises under $M T$.

\subsubsection{Productivity Shocks}

For productivity shocks, the effects on all the variables under all types of targeting are the same. It is clear from Table 8, that an increase in productivity, an increase in $x$, has no effect on any of the schedules. In particular, since firms agree to supply whatever output is demanded at the fixed contract price, $A S$ is not affected. Therefore, under all forms of levels targeting, productivity shocks have no effect on any variable except employment. Employment must be reduced because output demanded is unchanged. It follows that if the monetary authorities want to reduce or eliminate deviations in employment from its steady state value, they must choose a reaction function that includes employment deviations unlike the levels reaction function considered in this paper.

\subsection{The Combination Reaction Function}

\subsubsection{The Full Combination Model}

The combination model with wage and price stickiness is also obtained by assuming that there are both one-period wage and price contracts. The equations for both notional labor demand and notional labor supply are used along with all the other equations of the notional combination model in setting the contract wage equal to the expected wage and the contract price minus yesterday's price equal to the expected rate of inflation between yesterday and today based on yesterday's information, but both equations are omitted from the full combination model with wage and price stickiness. In particular, today's nominal wage is determined by taking expectations of the notional combination model in Table 2 with $\chi \rightarrow \infty$ based on yesterday's information. It follows from the discussion of the combination model with only wage stickiness that

$$
\begin{gathered}
w=w_{\mid-1}=p_{\mid-1}=\pi_{\mid-1}+p_{-1}, \\
p-p_{-1}=p_{\mid-1}-p_{-1}=\pi_{\mid-1} .
\end{gathered}
$$


The full combination model with wage and price stickiness is shown in Table 9. It is obtained by beginning with the notional combination model in Table 2, dropping the equations for notional labor supply and notional labor demand, and making use of the information in (44), (45), (52), and (53).

Table 9: Full Combination Model with Wage and Price Stickiness

$$
\begin{array}{llr}
y=(1-\alpha) l+x & \text { production function } & \mathrm{T} 9-1 \\
p-p_{-1}=\pi_{\mid-1} & \text { price setting } & \mathrm{T} 9-2 \\
w=\pi_{\mid-1}+p_{-1} & \text { wage setting } & \mathrm{T} 9-3 \\
\sigma y=-\left[i-\frac{\gamma_{\mu}}{\gamma_{\pi}+\gamma_{\mu}}(\phi y-\varepsilon i+v)\right]+U & \text { aggregate demand } & \mathrm{T} 9-4 \\
m=p+\phi y-\varepsilon i+v & \text { money market equilibrium } & \mathrm{T} 9-5 \\
i=\gamma_{\mu} \mu+\gamma_{y} y+\gamma_{\pi} \pi & \text { reaction function } & \mathrm{T} 9-6 \\
\pi=p-p_{-1} & \text { inflation definition } & \mathrm{T} 9-7 \\
\mu=m-m_{-1} & \text { money growth definition } & \mathrm{T} 9-8
\end{array}
$$

\subsubsection{The Schedules and a Relation for the Combination Model}

The equations for the schedules and a relation used to analyze the combination model with wage and price stickiness are shown in Table 10, and the schedules are plotted in $\pi, y$ space in Figure 1, Panel F.

Table 10: Schedules and Relation for Combination Model with Wage and Price Stickiness

$$
\begin{array}{lll}
\pi=\pi_{\mid-1} & A S \text { schedule } & \mathrm{T} 10-1 \\
\left(\sigma-\frac{\gamma_{\mu} \phi}{\gamma_{\pi}+\gamma_{\mu}}\right) y=-\left(1+\frac{\gamma_{\mu} \varepsilon}{\gamma_{\pi}+\gamma_{\mu}}\right) i+U+\frac{\gamma_{\mu}}{\gamma_{\pi}+\gamma_{\mu}} v & A D \text { schedule } & \mathrm{T} 10-2 \\
i=\frac{\gamma_{y}+\gamma_{\mu} \phi}{1+\gamma_{\mu} \varepsilon} y+\frac{\gamma_{\pi}+\gamma_{\mu}}{1+\gamma_{\mu} \varepsilon} \pi+\frac{\gamma_{\mu}}{1+\gamma_{\mu} \varepsilon} v-\frac{\gamma_{\pi}+\gamma_{\mu}}{1+\gamma_{\mu} \varepsilon} \pi_{\mid-1} & R \text { schedule } & \mathrm{T} 10-3 \\
\pi+y=0 & \Pi Y \text { constant schedule } & \mathrm{T} 10-4 \\
\pi+y=(1-\alpha) l+x+\pi_{\mid-1} & \Pi Y \text { to } L \text { relation } & \mathrm{T} 10-5
\end{array}
$$

There are differences between the aggregate supply schedule and the inflation plus output-employment relation in the combination model with wage and price stickiness and those in the combination model with wage stickiness considered in the previous section and these differences are essentially the same as the differences between the corresponding relationships in the levels models with the corresponding assumptions about nominal stickiness. The other three relationships in Table 10 are identical to the corresponding relationships in Table 6 and Figure 1, Panel B. $A S$ is horizontal because firms agree to produce any amount demanded at the inflation rate implied by the price fixed in the one-period contract. Its equation, (T10-1), is the identical to the price setting equation (T9-2). The inflation plus output-employment relation, (T10-5), in the combination model with wage and price stickiness is obtained by adding equations (T9-1) and (T9-2). If there is a productivity shock there is not a 
one-to-one relationship between the change in inflation plus output and the change in employment.

\subsubsection{Money Demand Shocks}

With both wage and price stickiness, just as with only wage stickiness, for money demand shocks, $\Pi T, Y T C$ and $\Pi Y T$ are equivalent, and $\mathcal{M T}$ is worse for all variables. Under $\mathcal{M T}$ (Figure 5, Panel A1) an increase in $v$ shifts the $R_{\mu}$ schedule down say to $R_{\mu, 1}$, and there is upward pressure on $i$. $R_{\mu}$ shifts up and $A D$ shifts down until they intersect somewhere on the marked part of the $A S_{0}$ schedule between points $a$ and $b$ and below the $\Pi Y$ schedule. In the new equilibrium, $i$ is higher and $y, \pi$, and, therefore, $\pi+y$ and $l$ are lower. Under $\Pi T, Y T C$ and $\Pi Y T$ (Figure 5, Panel A2), an increase in $v$ has virtually no effect on the $R_{\pi}, R_{y}$, and $R_{\pi y}$ schedules, respectively. There is virtually no shift in the $A D$ schedule. As a result, $i, y$, and $\pi$ and, therefore, $\pi+y$ and $l$ remain virtually unchanged.

\subsubsection{Goods Demand Shocks}

With both wage and price stickiness, just as with only wage stickiness, for goods demand shocks, $\Pi T, Y T C$, and $\Pi Y T$ are equivalent, and $\mathcal{M T}$ is worse for all variables. An increase in the demand for goods, an increase in $U$, causes the $A D$ schedule to shift right from $A D_{0}$ to $A D_{1}$ in Figure 5, Panels B1 and B2. Under $\mathcal{M} T$ (Figure 5, Panel B1), $i$ is increased in order to prevent an increase in $\mu$. The new equilibrium lies on the marked part of the $A S$ schedule between points $a$ and $b$ and above the $\Pi Y$ schedule. $\pi$ is unchanged, but $i, y$ and, therefore, $\pi+y$ and $l$ are all higher. Under PT, YTC, and PYT (Figure 5, Panel B2), the new equilibrium is at the same point as the initial equilibrium, point $a$. $i$ must be increased by enough to shift the $A D$ schedule all the way back to its original position. Since $\pi$ is fixed, stabilizing $\pi+y$ and, therefore, $l$ is equivalent to stabilizing $y$.

\subsubsection{Productivity Shocks}

For productivity shocks, the effects on all the variables under all types of targeting are the same in the combination model just as in the levels model. It is clear from Table 10 that an increase in productivity, an increase in $x$, has no effect on any of the schedules. Therefore, under all forms of combination targeting, productivity shocks have no effect on any variable except employment. Employment must be reduced because output demanded is unchanged. It follows that if the monetary authorities want to reduce or eliminate deviations in employment from its steady state value, they must choose a reaction function that includes employment deviations unlike both the levels and combination reaction functions considered in this paper. 


\section{The Model with Price Stickiness}

\subsection{The Levels Reaction Function}

The levels model with price stickiness is obtained by assuming that there are oneperiod price contracts but that wages are perfectly flexible. The equation for notional labor demand is used along with all the other equations of the notional levels model in setting the price, but it is omitted from the full levels model with price stickiness which is used for determining the other variables.

In particular, today's price is determined by taking expectations of the notional levels model in Table 2 with $\chi \rightarrow \infty$ based on yesterday's information and setting the price equal to the expected price. It follows from the discussion of the levels model with only wage stickiness that

$$
p=p_{\mid-1}=0 .
$$

The full set of equilibrium equations for the levels model with price stickiness are shown in Table 11. They are obtained by beginning with the notional levels model in Table 2, dropping the equation for notional labor demand, and making use of the information in (42) and (54).

Table 11: Full Levels Model with Price Stickiness

$\begin{array}{llc}y=(1-\alpha) l+x & \text { production function } & \mathrm{T} 11-1 \\ p=0 & \text { price setting } & \mathrm{T} 11-2 \\ w-p=\chi l+\sigma y-U & \text { labor supply } & \mathrm{T} 11-3 \\ \sigma y=-(i+p)+U & \text { aggregate demand } & \mathrm{T} 11-4 \\ m=p+\phi y-\varepsilon i+v & \text { money market equilibrium } & \mathrm{T} 11-5 \\ i=\lambda_{m} m+\lambda_{y} y+\lambda_{p} p & \text { reaction function } & \mathrm{T} 11-6\end{array}$

It follows from the information in Tables 7 and 11 that the aggregate supply, aggregate demand, reaction, and nominal-income-constant schedules and the nominal income-employment relationship for the levels model with only price stickiness are the same as those for the levels model with both wage and price stickiness. The only difference between Tables 7 and 11 is that equation T7-3 is not the same as equation T11-3. However, neither of these equations enters into the construction of the schedules and the nominal income-employment relation for its respective model. Therefore, the results for all variables except nominal wages for all kinds of shocks under all forms of targeting must be the same in the two models. The nominal wage is determined recursively by the labor supply function in the levels model with only price stickiness. It is predetermined in the levels model with both wage and price stickiness.

Under our presumption that labor supply is quite inelastic, any significant employment variation would have to be associated with significant nominal (and real) wage variation in the model with only price stickiness. ${ }^{28}$

\footnotetext{
${ }^{28}$ It seems unlikely to us that the workings of the economy are best described by sticky price-
} 


\subsection{The Combination Reaction Function}

A line of argument analogous to the line of argument in the previous subsection leads to the conclusion that for all the variables except nominal wages the results for the combination model with price stickiness are the same as the results for the combination model with both wage and price stickiness. The combination model with price stickiness is obtained by assuming that there are one-period price contracts but that wages are perfectly flexible. The equation for notional labor demand is used along with all the other equations of the notional combination model in setting the rate of inflation implied by the contract price, but it is omitted from the full combination model with price stickiness.

In particular, today's contract price is determined by taking expectations of the notional combination model in Table 2 with $\chi \rightarrow \infty$ based on yesterday's information and setting today's contract price minus yesterday's price equal to expected inflation between yesterday and today based on yesterday's information. It follows from the discussion of the combination model with only wage stickiness that

$$
p-p_{-1}=p_{\mid-1}-p_{-1}=\pi_{\mid-1} .
$$

The full set of equilibrium equations for the combination model with price stickiness are shown in Table 12. They are obtained by beginning with the notional combination model in Table 2, dropping the equation for notional labor demand, and making use of the information in (44), (45), and (55).

These equations are identical to those in Table 10 except that equation T12-3 is different from equation T10-3. The nominal wage is determined recursively by the labor supply function in the combination model with only price stickiness but is predetermined in the combination model with both wage and price stickiness.

Table 12: Full Combination Model with Price Stickiness

$$
\begin{array}{lll}
y=(1-\alpha) l+x & \text { production function } & \mathrm{T} 12-1 \\
p-p_{-1}=\pi_{-1} & \text { price setting } & \mathrm{T} 12-2 \\
w-p=\chi l+\sigma y-U & \text { labor supply } & \mathrm{T} 12-3 \\
\sigma y=-\left[i-\frac{\gamma_{\mu}}{\gamma_{\pi}+\gamma_{\mu}}(\phi y-\varepsilon i+v)\right]+U & \text { aggregate demand } & \mathrm{T} 12-4 \\
m=p+\phi y-\varepsilon i+v & \text { money market equilibrium } & \mathrm{T} 12-5 \\
i=\gamma_{\mu} \mu+\gamma_{y} y+\gamma_{\pi} \pi & \text { reaction function } & \mathrm{T} 12-6 \\
\pi=p-p_{-1} & \text { inflation definition } & \mathrm{T} 12-7 \\
\mu=m-m_{-1} & \text { money growth definition } & \mathrm{T} 12-8
\end{array}
$$

flexible wage models. However, given the recent popularity of these models, it is important to conduct further investigation of their empirical relevance. They cannot be dismissed simply by observing that nominal wage schedules are set in advance in some industries because firms in those industries can often vary the average hourly nominal wage paid by changing the relative amounts of straight-time and over-time labor they employ. 


\section{Conclusion}

In this exercise in stabilization economics, we analyze the choice of a monetary policy reaction function using the standard approach of Bailey (1962) and Poole (1970). The many individual results that are summarized in Table 13 provide a basis for some generalizations.

We consider two "general" specifications for the monetary policy reaction function: a "levels" specification and a "combination" specification. In both specifications, the interest rate is the instrument of monetary policy. In the levels specification, the interest rate responds to deviations of the money supply, the price level, and the level of output from chosen values. In the combination specification, the interest rate responds to deviations of the growth in the money supply, the rate of inflation, and the level of output from chosen values. These two specifications have almost all popular monetary policy reaction functions as special cases. The special cases that we consider here are keeping the interest rate instrument constant, referred to for brevity as "interest rate targeting," and using the interest rate instrument in targeting exactly one of the following: money, the price level, output, nominal income (output), money growth, inflation, and the sum of inflation and output.

Our framework is an optimizing model. We call our model "simple" because we assume one-period nominal stickiness, i.i.d. shocks, and no capital accumulation. It is "up to date" in the sense that it is a general equilibrium model with rational expectations that incorporates the increasingly popular paradigm with monopolistic competition among firms and monopsonistic competition among workers crafted by Blanchard and Kiyotaki (1987) using insights from Dixit and Stiglitz (1977). Nonetheless, it is properly viewed as an extension of earlier "disequilibrium models." There are three varieties of one-period nominal stickiness: wage stickiness, wage and price stickiness, and price stickiness, and three kinds of shocks: money demand shocks, goods demand shocks, and productivity shocks.

According to the standard approach, a given type of targeting is "better" than some other type for a given variable and kind of shock if it results in smaller deviations of the variable from its "target value." It is easy to imagine an alternative approach. In principle, the effects of shocks under alternative types of targeting can be compared using the utility function of the representative agent. However, the results of the standard approach are still of interest because they can be compared to those of earlier studies. There is a long tradition of using the expected values of variables in flexible price equilibria as "target values," that is, as the points of reference for normative stabilization economics. However, as several investigators have pointed out, under the new paradigm these values are not Pareto optimal, so not all deviations from them are welfare reducing. Since there is as yet no consensus on how to do "second best" stabilization economics, we follow the long tradition in selecting target values.

Some results are not surprising. Rankings may depend on the type of shock. For example, we confirm in our optimizing model the familiar results of Bailey (1962) and Poole (1970). No matter what the target variable, for money demand shocks, interest rate targeting is preferred to money supply targeting, but for goods demand 
shocks, money supply targeting is preferred to interest rate targeting. Rankings may also depend on the target variable. For example, we also confirm the striking results of Bean (1983) who considered the case in which wages are sticky but prices are flexible and notional labor supply is completely inelastic. If the target variable is employment, then for all shocks nominal income targeting or inflation plus income targeting is better than all other forms of targeting except in the special case in which it is exactly the same as money supply targeting. However, if the target variable is the price level, inflation, or output, then for productivity shocks, price level targeting, inflation targeting, or output targeting, respectively, is better than nominal income targeting or inflation plus output targeting.

Other results may be somewhat surprising. Given that wages are sticky, rankings depend on whether prices are sticky. If both wages and prices are sticky, output is demand-determined. In this situation, nominal income targeting and inflation plus output targeting are no better than several of the other forms of targeting that we consider, and for productivity shocks, none of the types of targeting does anything to help stabilize employment. In contrast, if prices are sticky, rankings do not depend on whether wages are sticky because output is demand-determined, and employment is given by the production function. If the nominal wage is flexible, it is determined recursively by the labor supply function.

We are in the midst of a period of renewed interest in stabilization economics. Even if the results that "we always thought were true" turn out to hold up, we will be better off for having scrutinized them further. 


\section{Table 13: Summary of Rankings of Types of Targeting}

\begin{tabular}{|c|c|c|c|c|}
\hline \multirow[b]{2}{*}{$\begin{array}{c}\text { sticky variable, } \\
\text { model type }\end{array}$} & \multirow[b]{2}{*}{$\begin{array}{l}\text { target } \\
\text { variable }\end{array}$} & \multicolumn{3}{|c|}{ kind of shock } \\
\hline & & money demand & goods demand & productivity \\
\hline \multirow{3}{*}{$\begin{array}{l}\text { wages, } \\
\text { levels }\end{array}$} & employment & $\left.\begin{array}{l}I T=P T \\
=Y T L \\
=P Y T\end{array}\right\} \succ M T^{\mathrm{a}}$ & $\left.\begin{array}{rl} & P T \\
= & Y T L \\
= & P Y T\end{array}\right\} \succ M T \succ I T$ & $\begin{array}{l}P Y T \succ \text { all except } M T \\
P Y T \succeq M T \\
I T \succ Y T L\end{array}$ \\
\hline & price level & $\begin{array}{l}\text { same as for } \\
\text { employment }\end{array}$ & $\begin{array}{l}\text { same as for } \\
\text { employment }\end{array}$ & $\begin{array}{l}P T \succ \text { all other } \\
P Y T \succ I T \succ Y T L\end{array}$ \\
\hline & output & $\begin{array}{l}\text { same as for } \\
\text { employment }\end{array}$ & $\begin{array}{l}\text { same as for } \\
\text { employment }\end{array}$ & $\begin{array}{l}Y T L \succ \text { all other } \\
I T \succ Y T L\end{array}$ \\
\hline \multirow{3}{*}{$\begin{array}{c}\text { wages, } \\
\text { combination }\end{array}$} & employment & $\left.\begin{array}{rl} & \Pi T \\
= & Y T C \\
= & \Pi Y T\end{array}\right\} \succ \mathcal{M} T^{\mathrm{b}}$ & $\left.\begin{array}{rl} & P T \\
= & Y T L \\
= & P Y T\end{array}\right\} \succ \mathcal{M T}$ & $\begin{array}{l}\Pi Y T \succeq \text { all except } \mathcal{M T} \\
\Pi Y T \succeq M T\end{array}$ \\
\hline & inflation & $\begin{array}{l}\text { same as for } \\
\text { employment }\end{array}$ & $\begin{array}{l}\text { same as for } \\
\text { employment }\end{array}$ & $\begin{array}{l}\Pi T \succ \text { all other } \\
\Pi Y T \succ Y T C\end{array}$ \\
\hline & output & $\begin{array}{l}\text { same as for } \\
\text { employment }\end{array}$ & $\begin{array}{l}\text { same as for } \\
\text { employment }\end{array}$ & $\begin{array}{l}Y T C \succ \text { all other } \\
\Pi Y T \succ \Pi T\end{array}$ \\
\hline $\begin{array}{c}\text { wages \& prices, } \\
\text { levels }\end{array}$ & $\begin{array}{l}\text { employment } \\
\text { price level } \\
\text { output }\end{array}$ & $\left.\begin{array}{r}I T=P T \\
=Y T L \\
=P Y T\end{array}\right\} \succ M T$ & $\begin{aligned} & P T \\
= & Y T L \\
= & P Y T\end{aligned}$ & all the same \\
\hline $\begin{array}{l}\text { wages \& prices, } \\
\text { combination }\end{array}$ & $\begin{array}{l}\text { employment } \\
\text { inflation } \\
\text { output }\end{array}$ & $\left.\begin{array}{rl} & \Pi T \\
= & Y T C \\
= & \Pi Y T\end{array}\right\}$ & $\begin{aligned} & P T \\
= & Y T L \\
= & P Y T\end{aligned}$ & all the same \\
\hline
\end{tabular}

${ }^{a} I T=$ "interest rate targeting," $\mathrm{PT}=$ price level targeting, YTL $=$ ouput targeting in the levels model,

$\mathrm{PYT}=$ nominal income targeting, $\mathrm{MT}=$ money supply targeting

${ }^{b} \Pi \mathrm{T}=$ price level targeting, YTC $=$ ouput targeting in the combination model,

$\Pi Y \mathrm{~T}=$ inflation plus output targeting, $\mathcal{M T}=$ money growth targeting 


\section{Appendix A}

In this Appendix we present solutions for some variables in the notional models and substantiate some of the claims made in the text. First, we obtain solutions for the output, employment, real wage, and real interest rate expected to prevail in period $t+j, j=1, \ldots, \infty$ based on period $t$ information in both the levels model and the combination model. Taking expectations of equations T2-1 through T2-4 for period $t+j, j=1, \ldots, \infty$ based on period $t$ information, taking account of our assumption that the shocks are i.i.d., and solving yield

$$
y_{t+j \mid t}=l_{t+j \mid t}=w_{t+j \mid t}-p_{t+j \mid t}=i_{t+j \mid t}-\left(p_{t+j+1 \mid t}-p_{t+j \mid t}\right)=0 .
$$

Using a procedure that is analogous in every way to the one used to obtain equation (A.1) except that expectations are taken based on period $t-1$ information, it can be shown that the output, employment, real wage, and real interest rate expected to prevail in period $t+j, j=0, \ldots, \infty$ based on period $t-1$ information in both the levels model and the combination model are

$$
y_{t+j \mid t-1}=l_{t+j \mid t-1}=w_{t+j \mid t-1}-p_{t+j \mid t-1}=i_{t+j \mid t-1}-\left(p_{t+j+1 \mid t-1}-p_{t+j \mid t-1}\right)=0 .
$$

Next, we obtain the solutions for the rest of the variables in the levels model. Substituting equation (T2-5) into equation (T2-6) for period $t+j$, taking expectations of the resulting equation based on period $t$ information, taking account of our assumption that the shocks are i.i.d., and making use of the solution for $i_{t+j \mid t}-\left(p_{t+j+1 \mid t}-p_{t+j \mid t}\right)$ in equation (A.1) yield the following difference equation:

$$
p_{t+j+1 \mid t}=\left(1+\frac{\lambda_{m}+\lambda_{p}}{1+\lambda_{m} \varepsilon}\right) p_{t+j \mid t}, \quad j=1, \ldots, \infty .
$$

By assumption, $\lambda_{m}+\lambda_{p} \geq 0$. If $\lambda_{m}+\lambda_{p}>0$, and if, in addition, it is assumed that there are no speculative bubbles, then it follows that the price level, the wage rate and the interest rate [from equation (A.1)], and the money supply [from equations (T2-5) and (A.1) and our assumption that shocks are i.i.d.] expected to prevail in period $t+j, j=1, \ldots, \infty$ based on period $t$ information are

$$
p_{t+j \mid t}=w_{t+j \mid t}=i_{t+j \mid t}=m_{t+j \mid t}=0 .
$$

Using a procedure that is analogous in every way to the one used to obtain equation (A.4) except that expectations are taken based on period $t-1$ information, it can be shown that the price level, wage rate, interest rate, and money supply expected to prevail in period $t+j, j=0, \ldots, \infty$ based on period $t-1$ information are

$$
p_{t+j \mid t-1}=w_{t+j \mid t-1}=i_{t+j \mid t-1}=m_{t+j \mid t-1}=0 .
$$

Now, we obtain the solutions for the rest of the variables in the combination model. Substituting equation (T2-9) into equation (T2-7) for period $t+j$, eliminating $m_{t+j}$ and $m_{t+j-1}$ using equation (T2-5), taking expectations of the resulting equation based 
on period $t$ information, making use of the solutions in equation (A.1) and the definition of inflation in equation (T2-8), and taking account of our assumption that the shocks are i.i.d. yield the following difference equation:

$$
\pi_{t+j+1 \mid t}=\left(\gamma_{\mu}+\gamma_{\pi}\right) \pi_{t+j \mid t}, \quad j=2, \ldots, \infty
$$

By assumption, $\gamma_{\mu}+\gamma_{\pi} \geq 0$. If $\gamma_{\mu}+\gamma_{\pi}>1$, and if, in addition, it is assumed that there are no speculative bubbles, then it follows that the inflation rate, the wage rate and the interest rate [from equation (A.1)], and the money growth rate [from equations (T2-5), (T2-9), (A.1), the assumption that the shocks are i.i.d., and solutions for other variables in equation (A.7)] expected to prevail in period $t+j, j=2, \ldots, \infty$ based on period $t$ information are

$$
\pi_{t+j \mid t}=w_{t+j \mid t}-p_{t+j-1 \mid t}-\pi_{t+j \mid t}=i_{t+j \mid t}=\mu_{t+j \mid t}=0 .
$$

It also follows that the inflation rate [from equations (T2-5), (T2-7), (T2-9), (A.1), (A.7), and the assumption that the shocks are i.i.d.], the wage rate and the interest rate [from equation (A.1) and (T2-8)], and the money growth rate [from equations (T2-7), (T2-9), (A.1), (A.7), and the assumption that the shocks are i.i.d.] expected to prevail in period $t+1$ based on period $t$ information are

$$
\begin{gathered}
\pi_{t+1 \mid t}=\frac{\gamma_{\mu}}{\gamma_{\pi}+\gamma_{\mu}}\left(\phi y_{t}-\varepsilon i_{t}+v_{t}\right), \quad w_{t+1 \mid t}-p_{t}-\pi_{t+1 \mid t}=0, \\
i_{t+1 \mid t}=0, \quad \mu_{t+1 \mid t}=-\left(\frac{\gamma_{\pi}}{\gamma_{\pi}+\gamma_{\mu}}\right)\left(\phi y_{t}-\varepsilon i_{t}+v_{t}\right) .
\end{gathered}
$$

Using a procedure that is analogous in every way to the one used to obtain equations (A.7) and (A.8) except that expectations are taken based on period $t-1$ information, it can be shown that the inflation rate, wage rate, interest rate, and money growth rate expected to prevail in period $t+j, j=1, \ldots, \infty$ based on period $t-1$ information are

$$
\pi_{t+j \mid t-1}=w_{t+j \mid t-1}-p_{t+j-1 \mid t-1}-\pi_{t+j \mid t-1}=i_{t+j \mid t-1}=\mu_{t+j \mid t-1}=0
$$

and that the inflation rate, wage rate, interest rate, and money growth rate expected to prevail in period $t$ based on period $t-1$ information are

$$
\begin{gathered}
\pi_{t \mid t-1}=\frac{\gamma_{\mu}}{\gamma_{\pi}+\gamma_{\mu}}\left(\phi y_{t-1}-\varepsilon i_{t-1}+v_{t-1}\right), \quad w_{t \mid t-1}-p_{t-1}-\pi_{t \mid t-1}=0 \\
i_{t \mid t-1}=0, \quad \mu_{t \mid t-1}=-\left(\frac{\gamma_{\pi}}{\gamma_{\pi}+\gamma_{\mu}}\right)\left(\phi y_{t-1}-\varepsilon i_{t-1}+v_{t-1}\right)
\end{gathered}
$$




\section{Appendix B}

In this Appendix we present solutions for models with wage stickiness and models with wage and price stickiness. For the levels models the solutions are for output, the price level, and the interest rate, and for the combination models the solutions are for output, inflation, and the interest rate. For both kind of models the solutions for employment can be derived from the solution for output and the production function.

$$
\begin{gathered}
\text { Wage Stickiness, Levels Model } \\
\Delta_{W, L}\left[\begin{array}{c}
y \\
p \\
i
\end{array}\right]=\left[\begin{array}{c}
-\xi \lambda_{m} v+\xi H U+(A+H) x \\
-\alpha \lambda_{m} v+\alpha H U-(\sigma H+F) x \\
(\alpha+\xi \sigma) \lambda_{m} v+(\alpha A+\xi F) U-(\sigma A-F) x
\end{array}\right] \\
\text { Wage Stickiness, Combination Model } \\
\Delta_{W, C}\left[\begin{array}{c}
y \\
\pi \\
i
\end{array}\right]=\left[\begin{array}{c}
-(J-1) \xi \gamma_{\mu} v+\xi J Z U+J Q x+\xi J Q \pi_{\mid-1} \\
-(J-1) \alpha \gamma_{\mu} v+\alpha J U U-\Delta_{W \& P, C} x+\alpha J Q \pi_{\mid-1} \\
\left(\alpha J+\xi\left(J \sigma+\gamma_{y}\right)\right) \gamma_{\mu} v+(\alpha J+\xi S) J U-J K x-\xi J K \pi_{\mid-1}
\end{array}\right]
\end{gathered}
$$

Wage and Price Stickiness, Levels Model

$$
\Delta_{W \& P, L}\left[\begin{array}{c}
y \\
p \\
i
\end{array}\right]=\left[\begin{array}{c}
-\lambda_{m} v+H U \\
0 \\
+\sigma \lambda_{m} v+F U
\end{array}\right]
$$

\section{Wage and Price Stickiness, Combination Model}

$$
\Delta_{W \& P, C}\left[\begin{array}{c}
y \\
\pi \\
i
\end{array}\right]=\left[\begin{array}{c}
-(J-1) \gamma_{\mu} v+J Z U+J Q \pi_{\mid-1} \\
0 \\
\left(J \sigma+\gamma_{y}\right) \gamma_{\mu} v+J S U-J K \pi_{\mid-1}
\end{array}\right]
$$

where

$$
\begin{array}{ccc}
\xi=1-\alpha, & A=\lambda_{p}+\lambda_{m}>1, & F=\lambda_{y}+\lambda_{m} \phi, \\
Q=J+\gamma_{\mu} \varepsilon, & K=J \sigma-\gamma_{\mu} \phi, & H=1+\lambda_{m} \varepsilon, \\
J=\gamma_{\mu}+\gamma_{\pi}>1, & Z=1+\gamma_{\mu} \varepsilon, & S=\gamma_{y}+\gamma_{\mu} \phi, \\
\Delta_{W, L}=\alpha(A+H)+\xi \Delta_{W \& P, L}>0, & \Delta_{W \& P, L}=\sigma H+F>0, \\
\Delta_{W, C}=\alpha J Q+\xi \Delta_{W \& P, C}>0, & \Delta_{W \& P, C}=(J-1) \gamma_{\mu} \phi+J Z \sigma+Q \gamma_{y}>0 .
\end{array}
$$




\section{References}

Bailey, M. (1962) National Income and the Price Level, McGraw-Hill, New York, 1st Edition.

Bean, C. (1983) "Targeting Nominal Income: An Appraisal", The Economic Journal, $93,806-19$.

Beaudry, P., and M. B. Devereux (1995) "Monopolistic Competition, Price Setting and the Effects of Real and Monetary Shocks", mimeo, University of British Columbia.

Benassy, J.-P. (1995) "Money and Wage Contracts in an Optimizing Model of the Business Cycle", Journal of Monetary Economics, 35, 303-315.

Blanchard, O. J., and N. Kiyotaki (1987) "Monopolistic Competition and the Effects of Aggregate Demand", American Economic Review, 77, 4, 647-666.

Bryant, R. (1980) Money and Monetary Policy in Interdependent Nations, Brookings Institution, Washington, D.C.

Bryant, R., P. Hooper, and C. Mann (1993) Evaluating Policy Regimes: New Research in Empirical Macroeconomics, Brookings Institution, Washington, D.C.

Canzoneri, M. B., and B. Diba (1997) "Fiscal Constraints on Central Bank Independence and Price Stability", in B. de Espana (ed.) Monetary Policy and Inflation in Spain, Banco de Espana, Madrid, (forthcoming).

Cho, J.-O. (1993) "Money and the Business Cycle with One-Period Nominal Contracts", Canadian Journal of Economics, 26, 638-659.

Cho, J.-O., and T. F. Cooley (1995) "The Business Cycle with Nominal Contracts", Economic Theory, 6, 13-33.

Clarida, R., J. Gali, and M. Gertler (1997) "The Science of Monetary Policy", processed, New York University.

Cooley, T. F., and G. D. Hansen (1995) "Money and the Business Cycle", in T. F. Cooley (ed.) Frontiers of Business Cycle Research, Princeton University Press, Princeton, N.J.

Dixit, A. K., and J. Stiglitz (1977) "Monopolistic Competition and Optimum Product Diversity", American Economic Review, 67, 297-308.

Dow, Jr., P. (1995) "The Demand and Liquidity Effects of Monetary Shocks", Journal of Monetary Economics, 36, 91-115.

Erceg, C. J. (1997) "Nominal Wage Rigidities and the Propagation of Monetary Distrubances", International Finance Discussion Papers, No. 590, Federal Reserve Board. 
Fischer, S. (1977) "Long-term Contracts, Rational Expectations and the Optimal Money Supply Rule", Journal of Political Economy, 85, 191-205.

Goodfriend, M., and R. King (1997) "The New Neoclassical Synthesis and the Role of Monetary Policy", in NBER Macroeconomics Annual, MIT Press, (forthcoming).

Gray, J. (1976) "Wage Indexation: A Macroeconomic Approach", Journal of Monetary Economics, 2, 221-35.

Henderson, D., and W. McKibbin (1993a) "An Assessment of Some Basic Monetary Policy Regime Pairs: Analytical and Simulation Results from Simple Multiregion Macroeconomic Models", in R. Bryant, P. Hooper, and C. Mann (eds.) Evaluating Policy Regimes: New Research in Empirical Macroeconomics, The Brookings Institution, Washington, D.C.

Henderson, D., and W. McKibbin (1993b) "A Comparison of Some Basic Monetary Policy Regimes for Open Economies: Implications of Different Degrees of Instrument Adjustment and Wage Persistence", in Carnegie-Rochester Series on Public Policy, Volume 39, 221-317.

Kim, J. (1997a) "Investment Adjustment Costs in a Simple Dynamic Model: Some Analytical Results", processed, Board of Governors of the Federal Reserve System.

Kim, J. (1997b) "Monetary Policy in a Stochastic Equilibrium Model with Real and Nominal Rigidities", processed, Board of Governors of the Federal Reserve System.

Kim, J. (1997c) "Three Sources of increasing Returns to Scale", Finance and Economics Discussion Series 1997-18, Board of Governors of the Federal Reserve System.

King, R. (1991) "Money and Business Cycles", processed, University of Rochester.

Koenig, E. F. (1996) "Targeting Nominal Income: A Closer Look", Economics Letters, $51,89-93$.

Leeper, E. (1991) "Equilibria under 'Active' and 'Passive' Monetary Policies", Journal of Monetary Economics, 27, 129-147.

Poole, W. (1970) "Optimal Choice of Monetary Policy Instruments in a Simple Stochastic Macro Model", Quarterly Journal of Economics, 84, 197-216.

Quandt, R. (1987) "Bibliography on Disequilibrium", mimeo, Princeton University.

Sargent, T., and N. Wallace (1981) "Some Unpleasant Monetarist Arithmetic", in Quarterly Review, Volume Fall, Federal Reserve Bank of Minneapolis, 1-17.

Sims, C. A. (1994) "A Simple Model for Study of the Determination of the Price Level and the Interaction of Monetary and Fiscal Policy", Economic Theory, 4, 381-99. 
Taylor, J. B. (1993) "Discretion versus Policy Rules in Practice", in CarnegieRochester Series on Public Policy, Volume 39, 195-214.

Woodford, M. (1996) "Control of the Public Debt: A Requirement for Price Stability?", NBER Working Paper 5684, National Bureau of Economic Research. 
Figure 1: Schedules

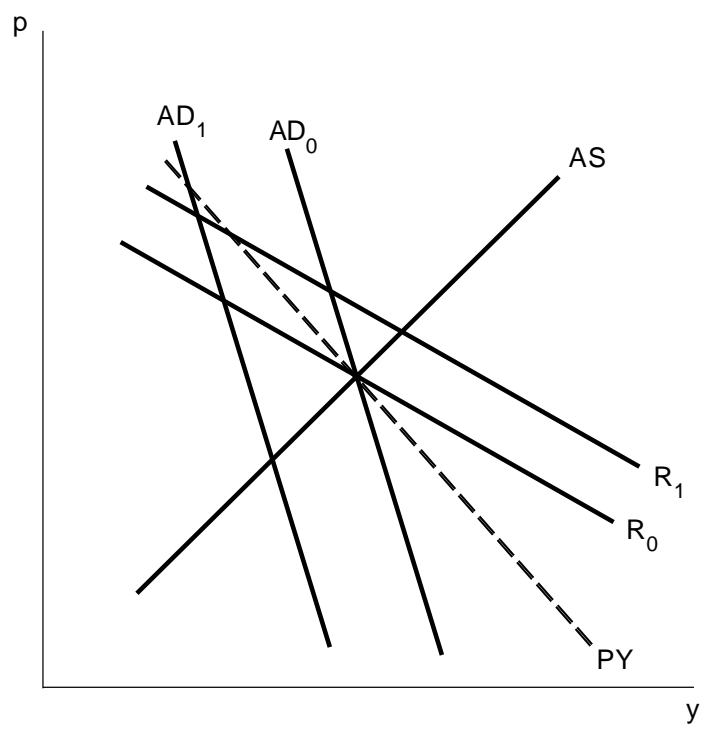

Panel A: Wage Stickiness, Levels Model

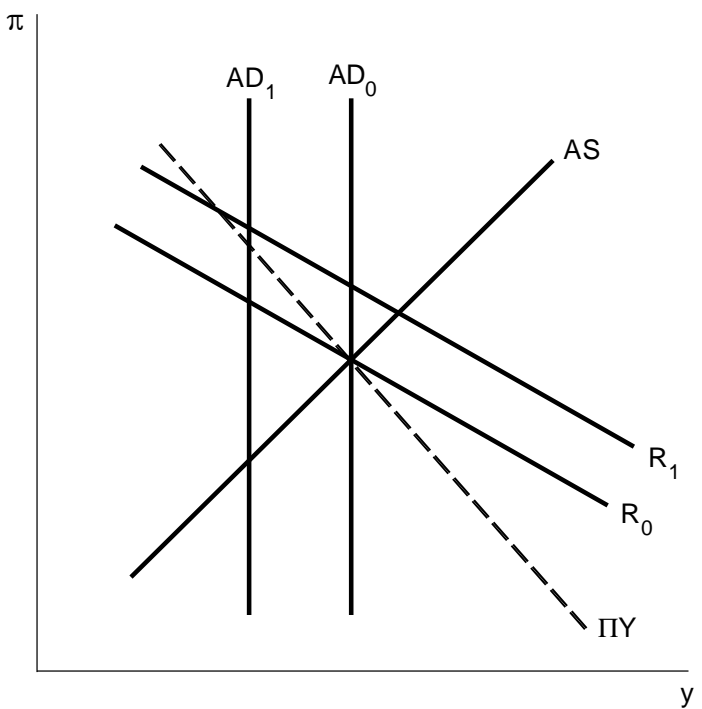

Panel B: Wage Stickiness, Combination Model

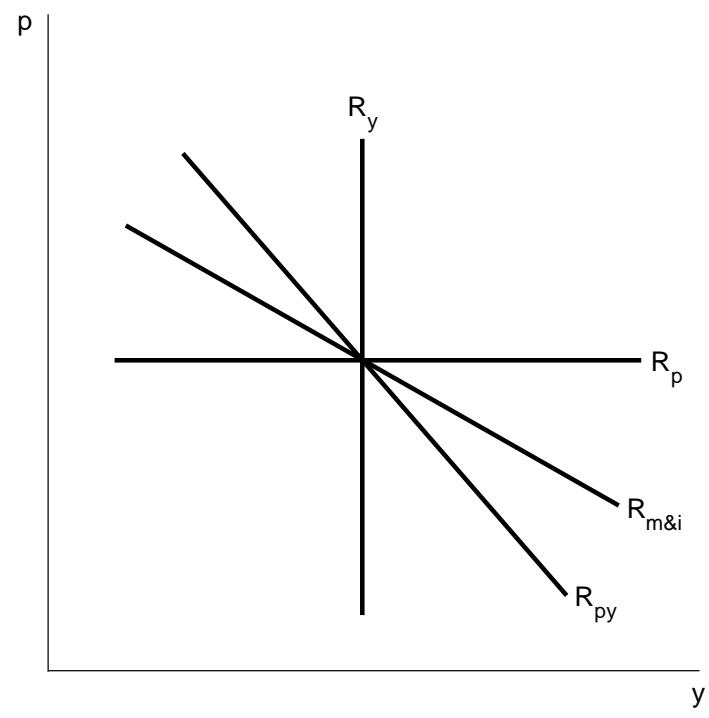

Panel C: Reaction Schedules, Levels Model

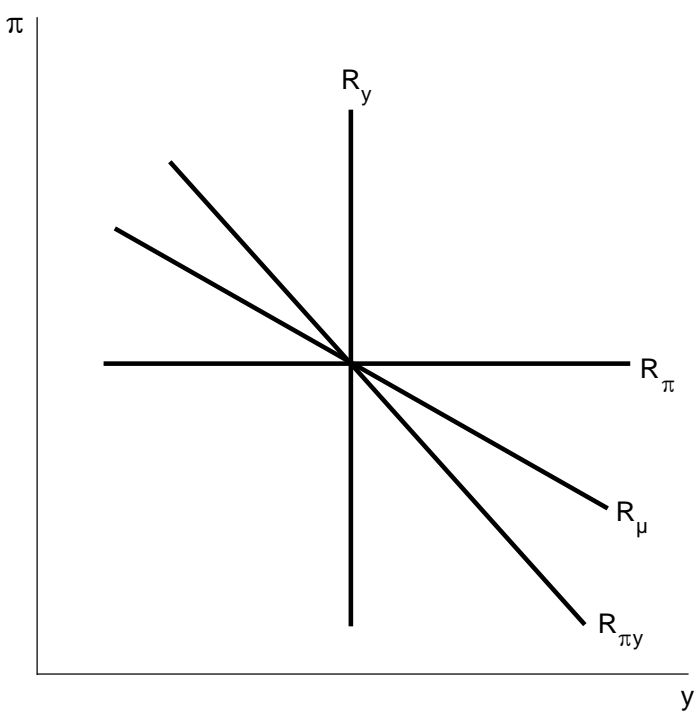

Panel D: Reaction Schedules, Combination Model

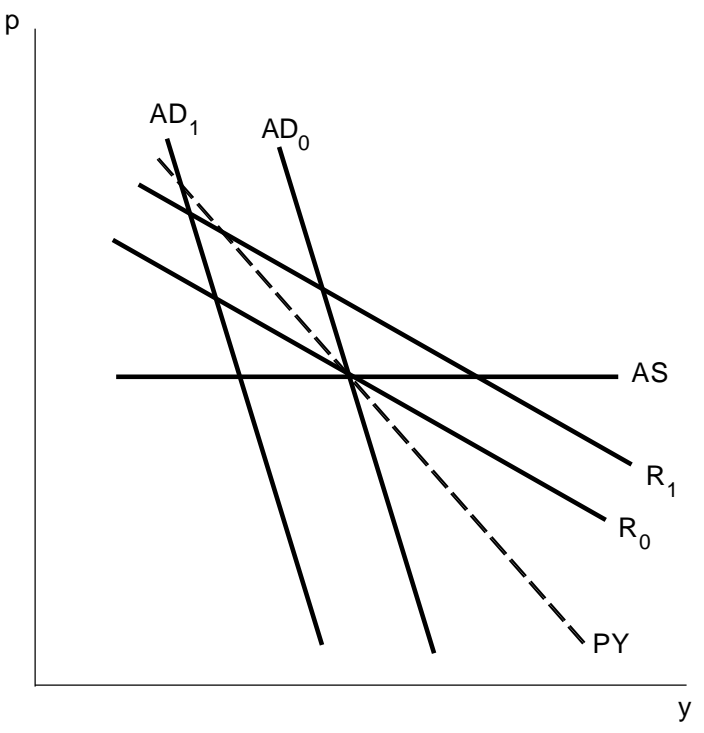

Panel E: Wage and Price Stickiness, Levels Model

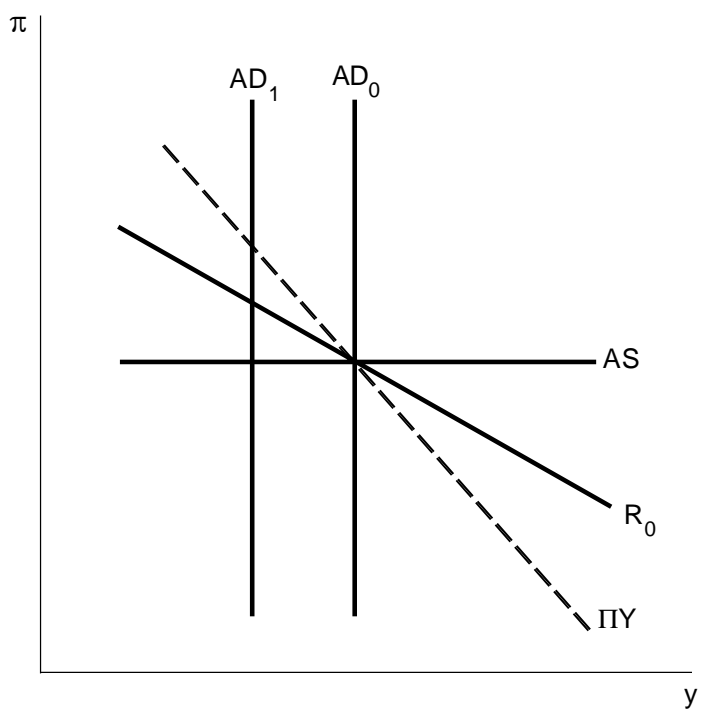

Panel F: Wage and Price Stickiness, Combination Model 
Figure 2: Effects of Shocks with Wage Stickiness, Levels Model

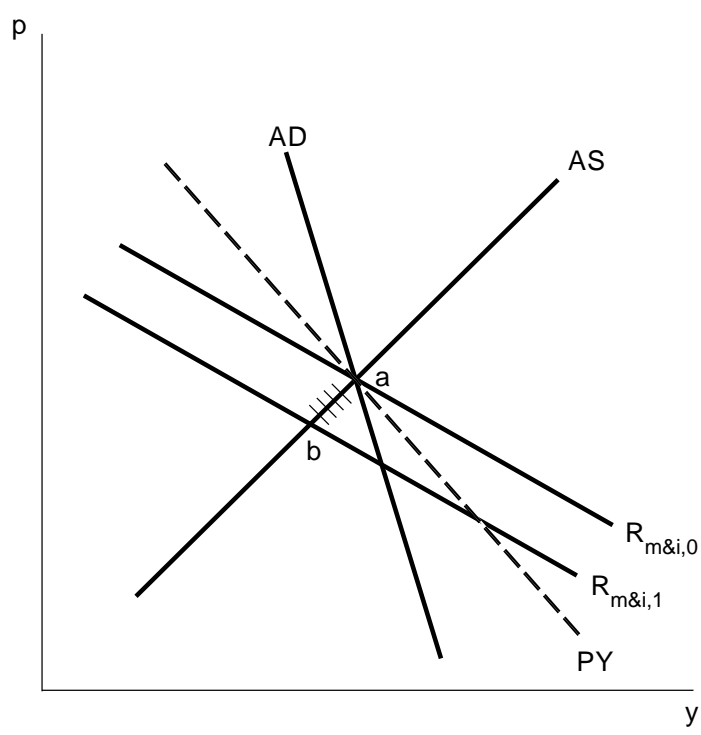

Panel A1: Money Demand; IT, MT

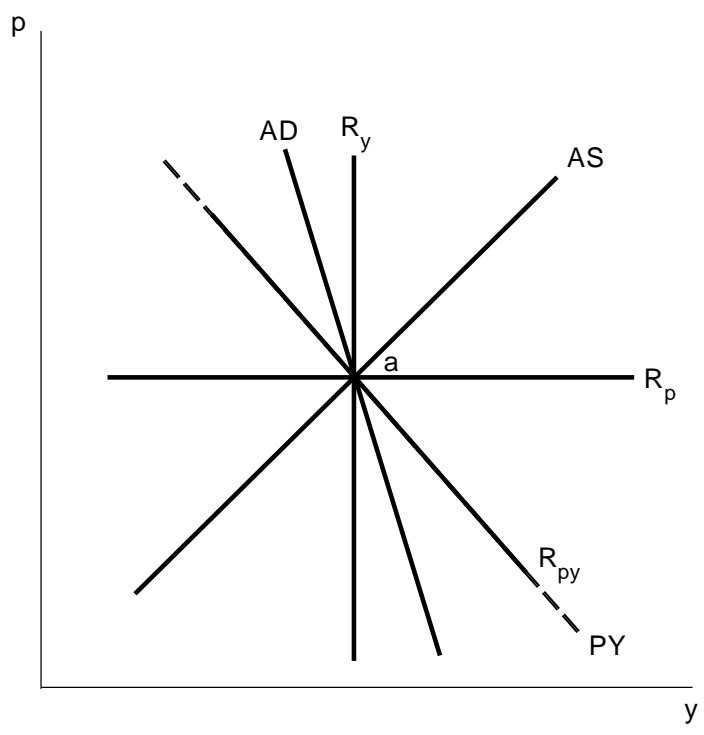

Panel A2: Money Demand; PT, YT, PYT

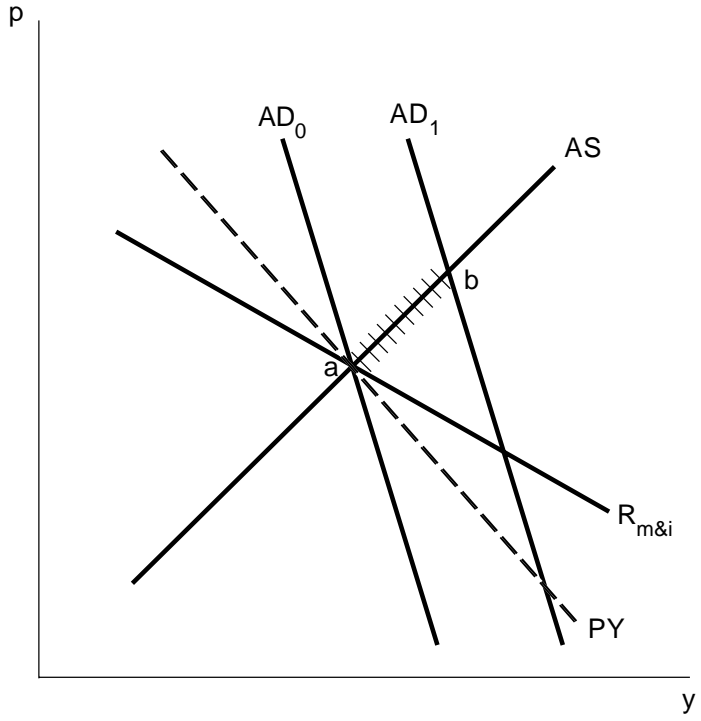

Panel B1: Goods Demand; IT, MT

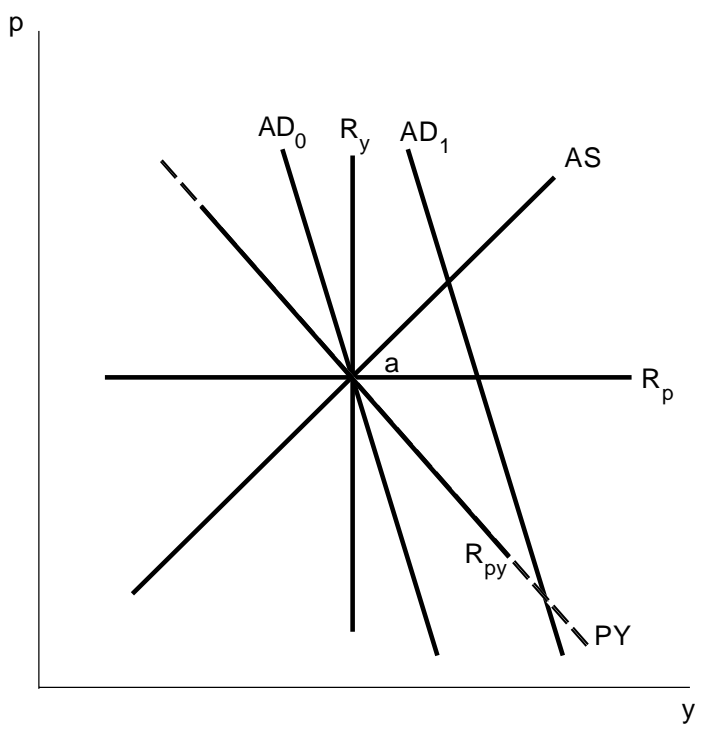

Panel B2: Goods Demand; PT, YT, PYT

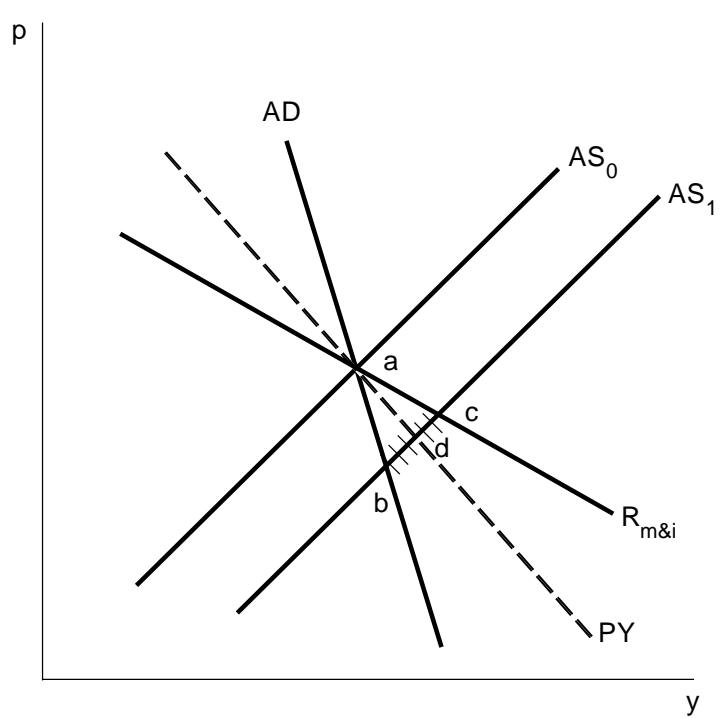

Panel C1: Productivity; IT, MT

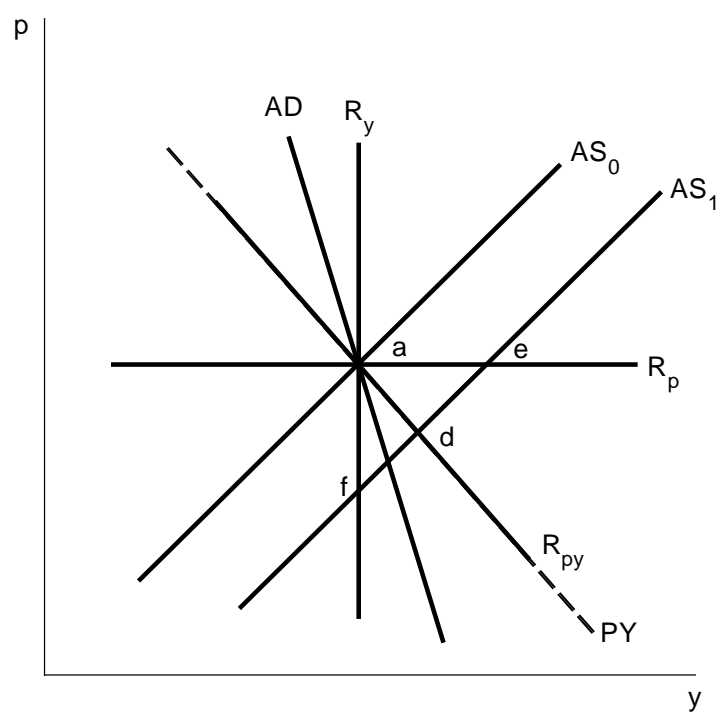

Panel C2: Productivity; PT, YT, PYT 


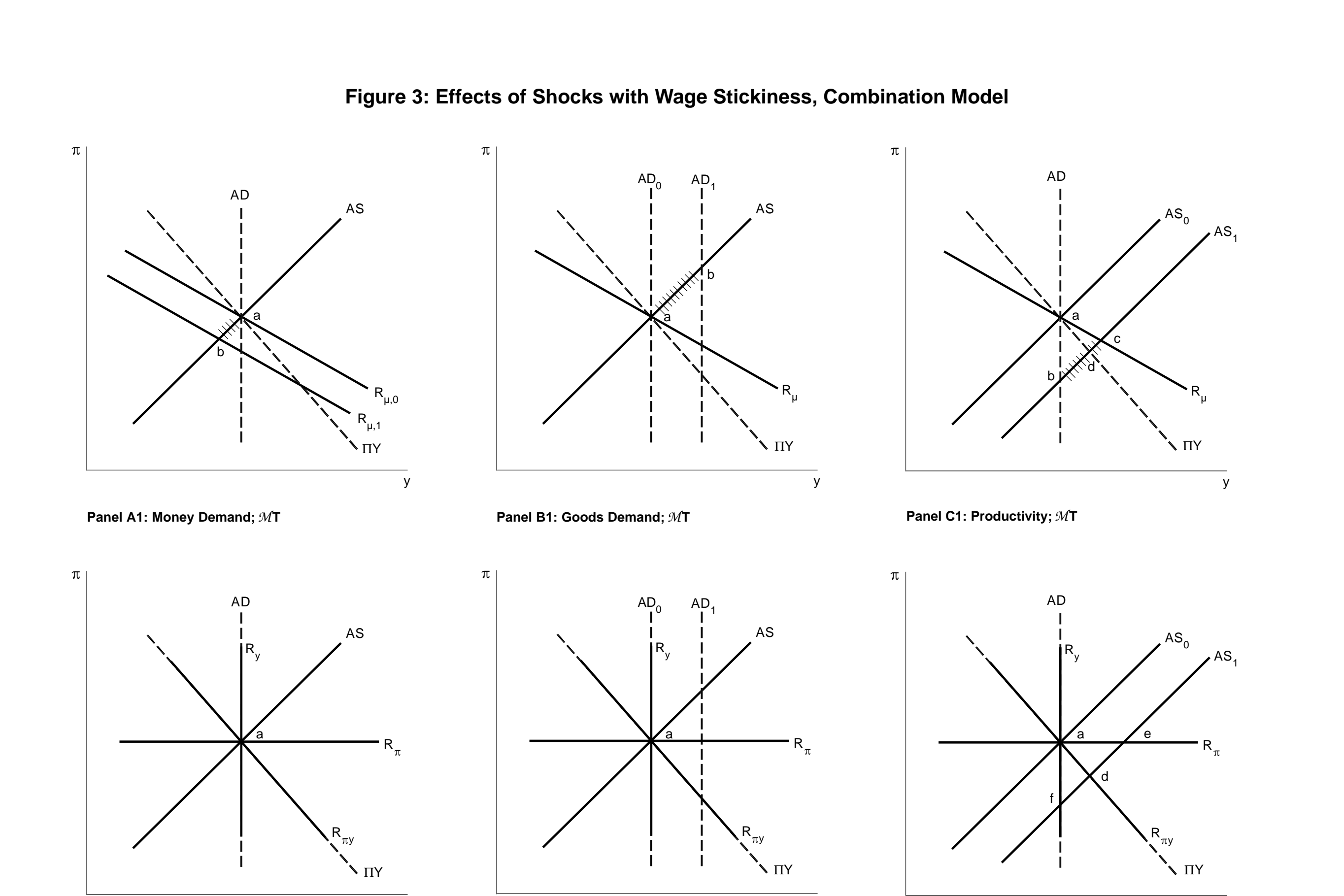


Figure 4: Effects of Shocks with Wage and Price Stickiness, Levels Model

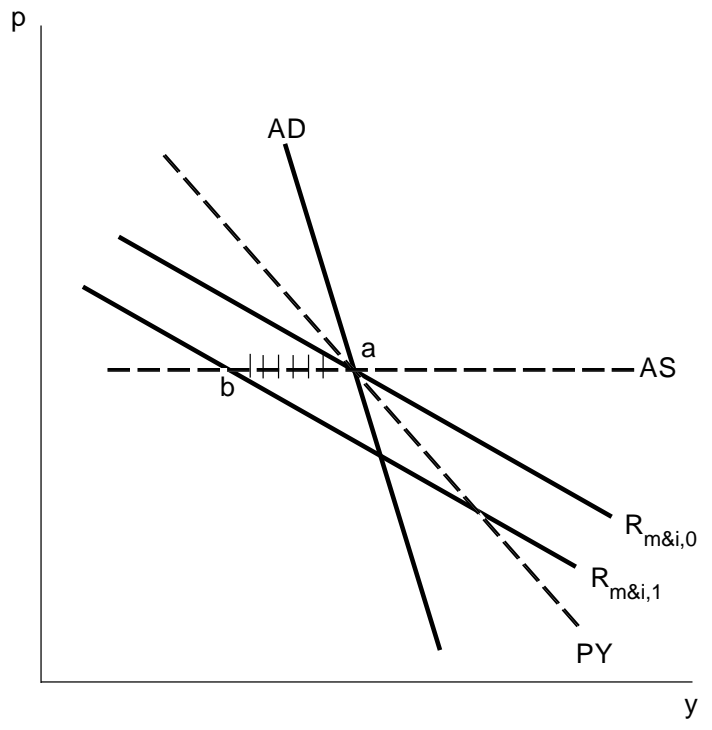

Panel A1: Money Demand; IT, MT

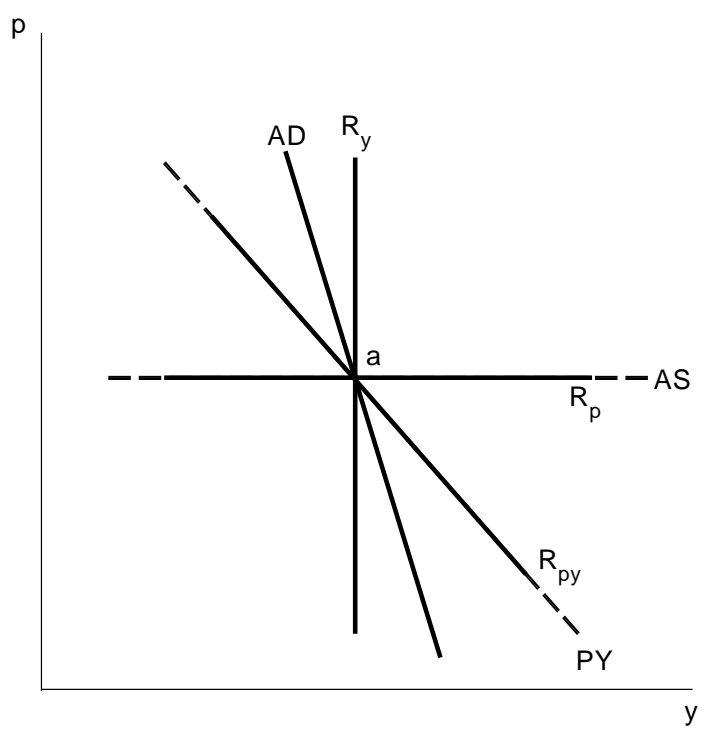

Panel A2: Money Demand; PT, YT, PYT

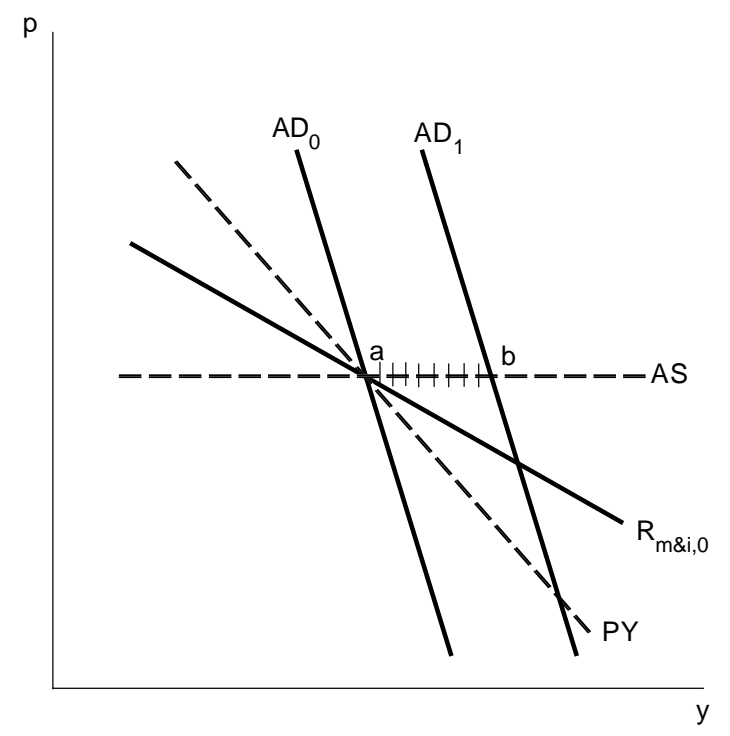

Panel B1: Goods Demand; IT, MT

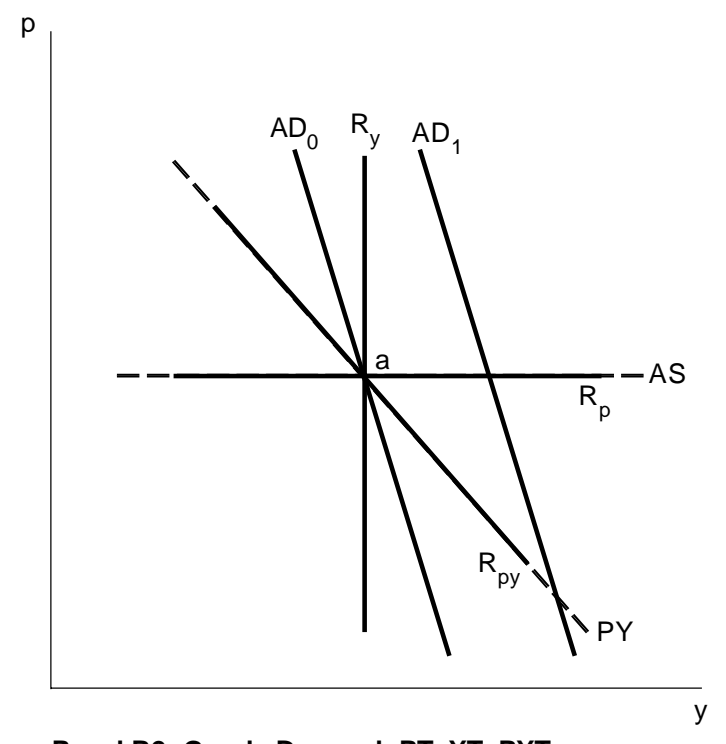

Panel B2: Goods Demand; PT, YT, PYT

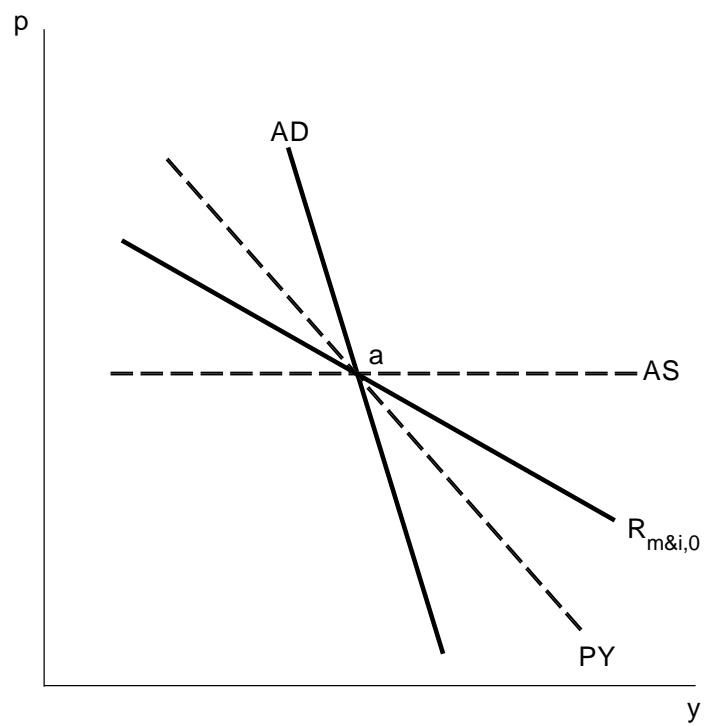

Panel C1: Productivity; IT, MT

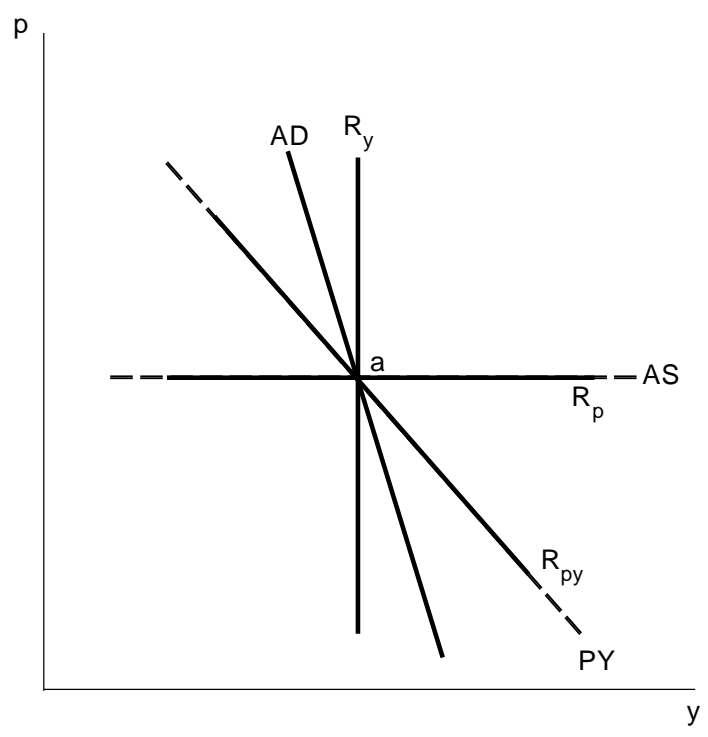

Panel C2: Productivity; PT, YT, PYT 
Figure 5: Effects of Shocks with Wage and Price Stickiness, Combination Model

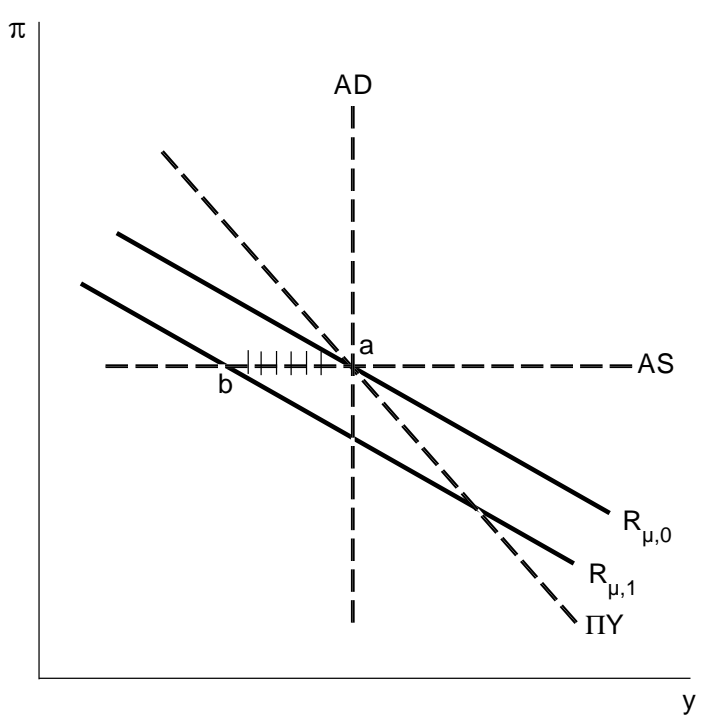

Panel A1: Money Demand; $\mathcal{M T}$

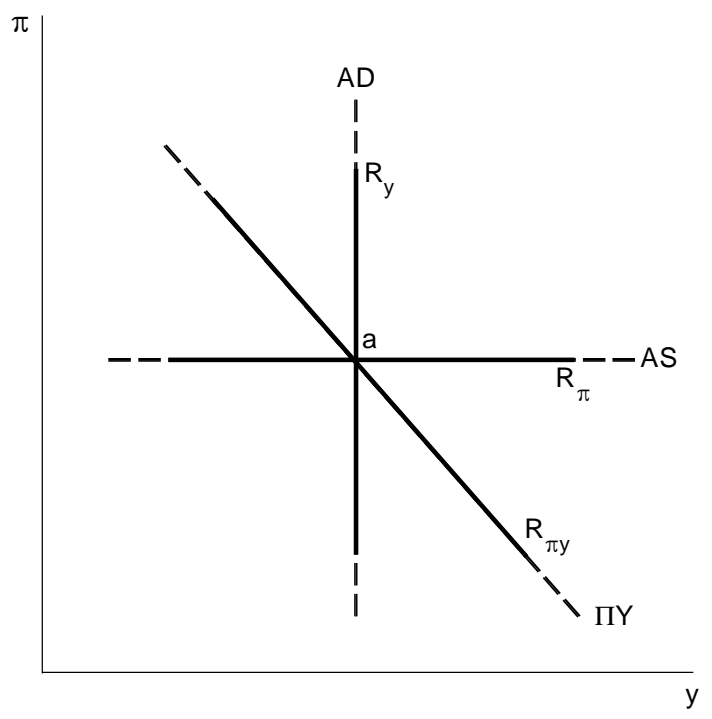

Panel A2: Money Demand; ПT, YT, ПYT

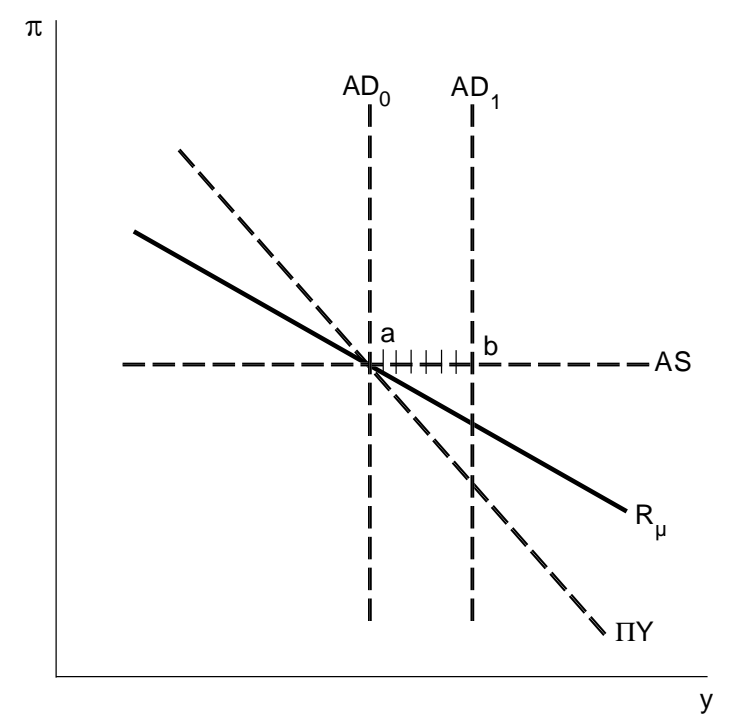

Panel B1: Goods Demand; $\mathcal{M T}$

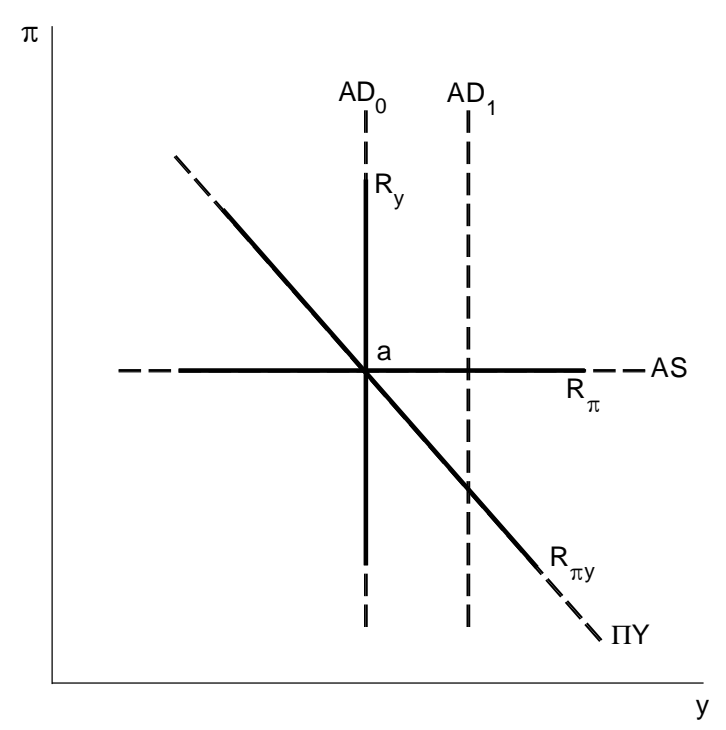

Panel B2: Goods Demand; ПT, YT, ПYT

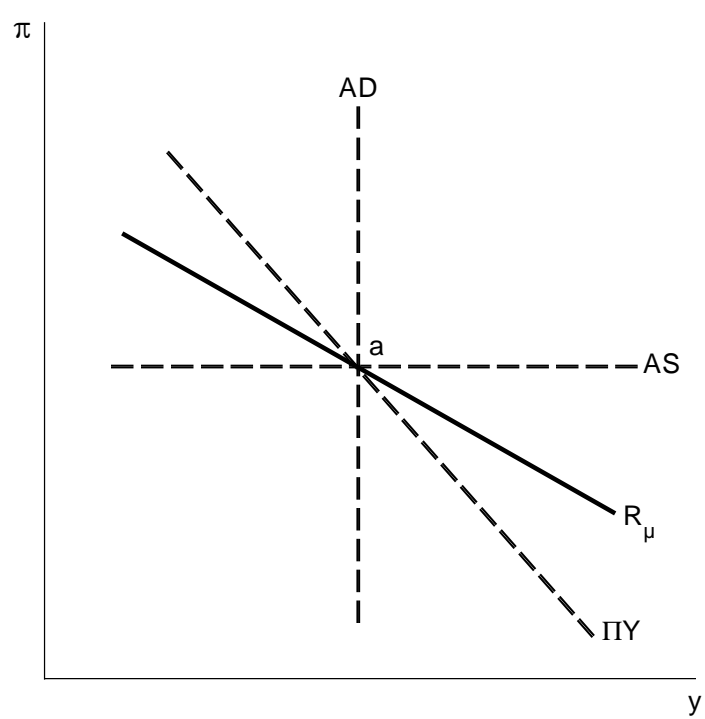

Panel C1: Productivity; $\mathcal{M T}$

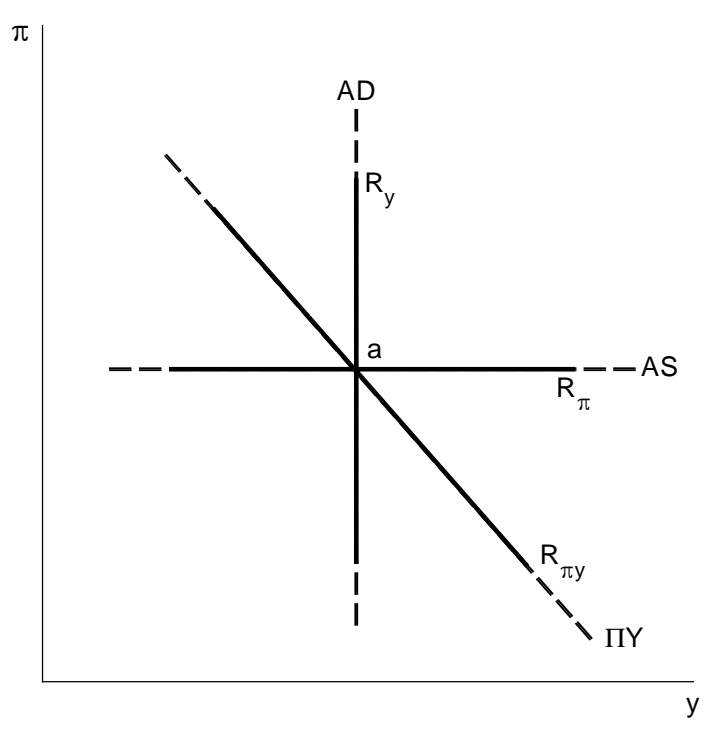

Panel C2: Productivity; ПТ, YT, ПYT 